\title{
Metal-catalyzed asymmetric sulfoxidation, epoxidation and hydroxylation by hydrogen peroxide
}

\author{
Hassan Srour, Paul Le Maux, Soizic Chevance and Gérard Simonneaux* \\ Institute of Sciences Chimiques of Rennes, Ingénierie Chimique et Molécules pour le vivant, UMR \\ 6226 CNRS, Campus de Beaulieu, 35042 Rennes cedex, France
}

\section{Contents}

1. Introduction 3

2. Asymmetric sulfoxidation 3

2.1 Iron systems 4

2.1.1 Non-heme systems 4

2.1.2 Iron porphyrins 5

$\begin{array}{ll}2.2 \text { Ruthenium catalysts } & 6\end{array}$

2.3 Manganese systems 6

2.3.1 Non-porphyrinic manganese systems 6

$\begin{array}{lll}\text { 2.3.2 Manganese porphyrins } & 7\end{array}$

2.4 Vanadium catalysts $\quad 8$

2.5 Niobium catalysts 9

2.6 Titanium catalysts 9

$\begin{array}{ll}2.7 \text { Platinum catalysts } & 11\end{array}$

2.8 Copper catalysts 11

$\begin{array}{ll}2.9 \text { Aluminium catalysts } & 11\end{array}$

$\begin{array}{ll}2.10 \text { Tungsten catalysts } & 11\end{array}$

3. Asymmetric epoxidation of alkenes 12

$\begin{array}{ll}3.1 \text { Iron systems } & 13\end{array}$

3.1.1 Non-heme systems 13

$\begin{array}{lll}3.1 .2 & \text { Iron porphyrins } & 14\end{array}$

$\begin{array}{ll}3.2 \text { Ruthenium catalysts } & 15\end{array}$

$\begin{array}{ll}\text { 3.3 Manganese systems } & 15\end{array}$ 
3.3.1 Non-porphyrinic manganese systems $\quad 15$

$\begin{array}{ll}\text { 3.3.2 Manganese porphyrins } & 17\end{array}$

$\begin{array}{ll}3.4 \text { Scandium catalysts } & 18\end{array}$

$\begin{array}{ll}3.5 \text { Niobium catalysts } & 18\end{array}$

$\begin{array}{ll}3.6 \text { Titanium catalysts } & 18\end{array}$

$\begin{array}{ll}3.7 \text { Platinum catalysts } & 19\end{array}$

$\begin{array}{ll}3.8 \text { Copper catalysts } & 19\end{array}$

$\begin{array}{ll}3.9 \text { Rhenium catalysts } & 19\end{array}$

4. Asymmetric dihydroxylation of alkenes 20

$\begin{array}{ll}4.1 \text { Iron catalysts } & 21\end{array}$

$\begin{array}{ll}4.2 \text { Manganese catalysts } & 21\end{array}$

$\begin{array}{ll}4.3 \text { Osmium catalysts } & 21\end{array}$

5. Asymmetric hydroxylation of alkanes 22

$\begin{array}{ll}\text { 5.1 Non-heme systems } & 22\end{array}$

5.2 Iron and manganese porphyrins $\quad 22$

6. Conclusion 24

7. References 25

\begin{abstract}
The development of environmentally benign reactions is an important goal in synthetic organic chemistry and chemical engineering. However, catalytic enantioselective oxidations using transition-metal complexes are limited when the oxidant is hydrogen peroxide. The two main difficulties of using hydrogen peroxide in the presence of transition metal complexes are the homolytic cleavage generating $\mathrm{OH}$ radicals and the catalase reaction with formation of dioxygen. The current applications of asymmetric sulfoxidation, epoxidation, dihydroxylation of alkenes and hydroxylation will be herein reported. Use of non-heme systems will be presented. The possibility of asymmetric oxidation catalyzed by metalloporphyrins will also be discussed.
\end{abstract}

Keywords: Hydrogen peroxide; Metal complex; Asymmetric sulfoxidation; Asymmetric epoxidation; Asymmetric dihydroxylation; Metalloporphyrin 


\section{Introduction}

Oxidation catalysis is an important domain of chemical research. Numerous applications are nowadays in the fine chemical industry. The nature of the terminal oxidant is often crucial for the efficiency of oxidation reactions, and typical oxygen-transfer reagents include alkyl hydroperoxides, iodosylbenzene, peroxycarboxylic acids, hypochlorite, dioxygen and oxone. Despite significant efforts to utilize $\mathrm{H}_{2} \mathrm{O}_{2}$ in asymmetric oxidation catalysis, only a few general systems work well with this abundant, environmentally benign, atom-economical and relatively safe oxidant [1,2]. However hydrogen peroxide is probably the best terminal oxidant after dioxygen with respect to environmental and economic consideration $[1,3]$. It is also very attractive because its solubility in water and many organic solvents is quite large. As a result, oxidation systems that use hydrogen peroxide in conjunction with catalytic amount of cheap, relatively non-toxic metals such as iron, and to a less extent manganese, are highly desired for application in pharmaceutical area. Despite significant efforts to utilize $\mathrm{H}_{2} \mathrm{O}_{2}$ in asymmetric oxidation catalysis, only a few general systems are efficient with this environmentally benign oxidant [2]. The only side-product when using hydrogen peroxide as oxidant is a water molecule. However, the two main difficulties of using hydrogen peroxide in the presence of transition metal complexes are the homolytic cleavage generating $\mathrm{OH}$ radicals and the catalase reaction with formation of dioxygen [4].

Recently, however, there is a revival in developing original and efficient system in asymmetric catalysis [5]. Thus we have now the development of new generations of metal complexes which are able to selectively catalyze various oxidation reactions. In this review the focus is on promising asymmetric oxidation systems using hydrogen peroxide as oxidant and metal-based catalysts. Organic catalysts designed for asymmetric oxidation may also operate with hydrogen peroxide [2, 6-8] but they are beyond the scope of this review. Direct use of hydrogen peroxide as primary oxidant, in the Baeyer-Villiger oxidation has also been reported [9]. However, only a few catalysts are used in combination with hydrogen peroxide as the oxidant for enantioselective reactions [10-12]. Consequently, this reaction will not be developed in the present review, there are excellent reviews on this topic $[9,13,14]$.

\section{Asymmetric sulfoxidation}


The selective oxidation of sulfides to sulfoxides has attracted much attention over the years after the pioneering work of Kagan [15] and Modena [16]. Hydrogen peroxide, however, has to be used in a controlled manner, due to the possibility of an over-oxidation reaction since possible formation of sulfones is also observed in various reactions as byproducts [17]. This formation may suggest the existence of a kinetic resolution process during the course of the reaction. To investigate this aspect, the time dependence of the asymmetric process should be studied in more details. Sulfoxides also constitute chiral synthons in organic synthesis for the preparation of biologically active compounds [18]. They also serve as chiral auxiliaries [19]. There are recent and excellent reviews on this topic [17,18,20-23].

\subsection{Iron systems}

Among all methods described so far [17], the asymmetric oxidation of sulfides by metal catalysts is one of the most attractive routes to optically active sulfoxides, and quite recently, even nontoxic and inexpensive iron complexes have been developed successfully, using hydrogen peroxide as oxidant [24-26]. Recent results will be separated in two parts: non-heme systems and iron porphyrin catalysts.

\subsubsection{Non-heme systems}

The iron complex $\left[\mathrm{FeO}(\mathrm{pb})_{4}\left(\mathrm{H}_{2} \mathrm{O}\right)_{2}\right] \mathrm{ClO}_{4}(\mathrm{pb}=(-)-4,5$-pinene-2,2'-bipyridine $)$ was reported in 1999 by Fontecave and coworkers [27, 28] as catalyst for the sulfide oxidation with hydrogen peroxide with yields ranging from 45 to $90 \%$, but the enantioselectivity was only modest (ee $=40 \%$ ) (Scheme 1 ). The catalytic properties of the mononuclear complex were compared to those of its related dinuclear analogue. Each system generates specific peroxo adducts but the latter was found more reactive and enantioselective than its mononuclear counterpart [29].

Since then several examples of asymmetric oxidation of sulfides using $\mathrm{H}_{2} \mathrm{O}_{2}$ catalyzed by non-heme chiral iron complexes have been reported by Bolm and co-workers (Scheme 2) $[18,24,25,30]$. Despite the remarkable application of the chiral iron complexes with $\mathrm{H}_{2} \mathrm{O}_{2}$, the rather low reaction yields and the moderate enantioselectivities remained problematic. These limitations, however, could be overcome by the use of additives such as benzoic acid derivatives or their lithium salts [24]. After a comprehensive screening of carboxylic acids, p- 
methoxybenzoic acid or the corresponding lithium carboxylate was found to be the most efficient additive in this transformation. The use of this additive dramatically improved the reaction yields as well as the enantioselectivities [25]. An iron-catalyzed asymmetric sulfide oxidation was also found to be the key step in the synthesis of the non-steroidal antiinflammatory drug Sulindac (Figure 1) [31]. Both enantiomers of the chiral product can be prepared with $92 \%$ ee in good yield.

Applicable asymmetric oxidation of sulfides using a $\mathrm{Fe}$ (salan) complex/aqueous hydrogen peroxide system was also reported in water by Egami and Katsuki [26]. Remarkably, the reactions were carried out in water using a chiral iron catalyst without a surfactant and higher enantioselectivity was observed in water than in methanol. After optimization, the reaction proceeds with high enantioselectivity (87-94\% ee) (Scheme 3) [32].

The enantioselective oxidation of thioanisole to methyl phenyl sulfoxide has been recently realized by using new iron(III) complexes, generated in situ from primary aminederived non-symmetrical Schiff base ligands (Figure 2) and aqueous $\mathrm{H}_{2} \mathrm{O}_{2}$ as environmentally benign oxidant [33]. Moderate yields (up to 69\%) and reasonable enantiomeric excesses (up to $54 \%$ ee) could be achieved when the reaction was carried out in THF and progressive addition of $\mathrm{H}_{2} \mathrm{O}_{2}$ using a syringe pump within 5 or $7 \mathrm{~h}$.

\subsubsection{Iron porphyrins}

Metalloporphyrins, widely studied as models of hemes or cytochrome P-450 [34], have been known to exhibit the catalytic activity for monooxygenation, proceeding via the formation of high valency metal-oxygen complex intermediates. However the asymmetric oxidation of sulfides catalyzed by chiral iron porphyrin was still unprecedented until 2011 when the oxidant is hydrogen peroxide. This is quite surprising since the first metalloporphyrin-catalyzed oxygenation with hydrogen peroxide reported the formation of sulfoxide from sulfide [35]. However, it should be noted that the enzymatic oxidation of sulfides to optically active sulfoxides catalyzed by peroxidases [36-39] and other heme proteins $[19,40]$ was previously reported. Vanadium-based semi-synthetic enzymes catalyzed the enantioselective oxidation of prochiral sulfides with $\mathrm{H}_{2} \mathrm{O}_{2}$ affording the S-sulfoxide, e.g. in $66 \%$ ee, at quantitative conversion of thioanisole [41].

There are previously reported asymmetric homogeneous iron-porphyrin-catalyzed sulfide oxidations in the literature with iodosylbenzene as oxidant [42-47]. Many iron porphyrin- $\mathrm{H}_{2} \mathrm{O}_{2}$ systems have been studied to get information on the mechanism and nature of 
the active intermediates $[4,48-50]$. The two main obstacles when using hydrogen peroxide are the high activity of many first-row transition metals in its decomposition thereof, the so-called catalase reaction [5] and the catalyst destruction by hydroxyl radicals readily released by homolytic $\mathrm{H}_{2} \mathrm{O}_{2}$ decomposition. However, the first enantioselective iron-porphyrin-catalyzed sulfoxidation (ee up to 90\%) with aqueous hydrogen peroxide was recently reported by Simonneaux group [51]. The reactions were carried out in methanol and water using chiral water-soluble iron porphyrins as catalysts (Figure 3). This investigation of $\mathrm{H}_{2} \mathrm{O}_{2}$ asymmetric oxidation of sulfides in a protic solvent shows the practicability of the process (absence of excess of oxidant and substrate, small reaction time and room temperature reaction) even though the chiral catalyst does not bear a robust porphyrin ligand. A protection of the oxoiron(IV) cation radical intermediate from the two norbornane groups fused to the central benzene ring is suggested since a similar reaction catalyzed by FeClTPPS (tetra- $p$ sulfonatophenylporphyrin iron chloride) yields to the destruction of the porphyrin ring [52].

\subsection{Ruthenium catalysts}

With the exception of a few specific systems [53], the combination of ruthenium catalysts with hydrogen peroxide has not been well developed owing to rapid decomposition of hydrogen peroxide [54]. However, for the first time the potential of the "chiral-at-metal" cis- $\left[\mathrm{Ru}(\mathrm{dmp})_{2}-\left(\mathrm{CH}_{3} \mathrm{CN}\right)_{2}\right]^{2+}$ complex (Figure 4), with achiral phenanthroline ligands, in pure enantiomeric form, as a catalyst for enantioselective sulfoxidation by hydrogen peroxide was reported by Fontecave and co-workers [55]. Even though the enantiomeric excesses are small $(<20 \%)$, this work also provides the first experimental demonstration that the chiral information carried by a stereogenic metal center can be catalytically transferred to molecules during stereoselective oxidation [55].

\subsection{Manganese systems}

\subsubsection{Non-porphyrinic manganese systems}

Jacobsen was first to successfully use chiral salen manganese catalysts (Figure 5) in asymmetric sulfide oxidation using complexes that also exhibited highly selective asymmetric epoxidation [56]. Modest enantioselectivity was observed with $34-68 \%$ ee using unbuffered hydrogen peroxide as the stoichiometric oxidant and acetonitrile as solvent.

More recently, several manganese complexes prepared from an easy accessible diimine ligand (Scheme 4) proved to be catalysts for asymmetric sulfoxidation by hydrogen 
peroxide. Enantiomeric excesses ranging from $5 \%$ to $62 \%$ were obtained with a variety of alkyl sulfides [57].

In situ prepared manganese complexes with chiral amino alcohols as ligands have also been used in the catalytic oxidation of sulfides to sulfoxides using hydrogen peroxide at $0^{\circ} \mathrm{C}$ in acetone. Methyl phenyl sulfoxide was obtained in 55\% yield and turnover numbers up to 250, while the formation of sulfone is almost suppressed but with low enantiomeric excess $(<20 \%)[58]$.

Very recently, a chiral sulfonato-(salen)Mn(III) complex was grafted onto a flexible polysiloxane, then axially coordinated by 3-aminopropyl functionalized silica gel, and

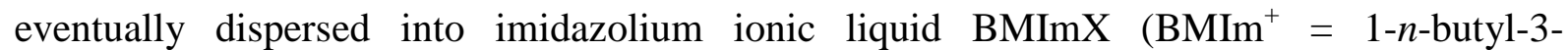
methylimidazolium; $\mathrm{X}^{-}=\mathrm{BF}_{4}^{-}$), which produced a new triply immobilized (salen)Mn(III) catalyst for asymmetric sulfoxidation reactions [59]. In general, these reactions proceeded smoothly (TOF values >10) and exhibited eevalues up to $92 \%$.

It has also been reported the incorporation of an achiral $\mathrm{Mn}$ (salen) into apo-Mb using a dual covalent anchoring approach [60]. The resulting artificial enzyme displays higher enantioselectivity than those constructed using either a noncovalent or single covalent anchoring approach $[61,62]$.

\subsubsection{Manganese porphyrins}

The investigation of hydrogen peroxide oxidation of sulfides in a protic solvent shows that catalysis by $\mathrm{Mn}(\mathrm{III})$ tetraarylporphyrins can provide an interesting route to the transformation of mustard and related sulfides into sulfoxides and sulfones [63]. However, until very recently [64], the asymmetric oxidation of sulfides catalyzed by chiral manganese porphyrin is still unprecedented when the oxidant is $\mathrm{H}_{2} \mathrm{O}_{2}$ although there is one example of sulfoxidation with chiral manganese corroles [65]. The enantioselective synthesis of the pharmacology important $R$-modafinil (Figure 1), in $88 \%$ yield and $73 \%$ ee was reported as an application of the corrole manganese catalyst. An efficient asymmetric oxidation of sulfides catalyzed by water-soluble chiral manganese porphyrin (Figure 3) was also carried out in presence of cheap and environmentally benign oxidant $\mathrm{H}_{2} \mathrm{O}_{2}$ at $25^{\circ} \mathrm{C}$ [64]. Prochiral sulfides were converted to sulfoxides with up to $100 \%$ conversion and up to $57 \%$ enantiomeric excess. The study demonstrated the necessity of water as solvent and imidazole as co-catalyst. Application to the preparation of the optically active drug, sulindac (Figure 1), was also demonstrated [64]. 
Albumin-conjugated corrole [65,66] and porphyrin [67] manganese complexes have also been found useful for asymmetric oxidation of sulfides. Using hydrogen peroxide as oxidant, sulfoxides were obtained in up to $74 \%$ ee [66].

\subsection{Vanadium catalysts}

There are two reviews on vanadium-catalyzed asymmetric oxidation reported by Bolm in 2003 [68] and Volcho in 2009 [69]. A vanadium(IV)-Schiff base complex (Figure 6) was successfully applied for the first time in 1995 for the oxidation of thioanisole to the corresponding sulfoxide by the use of hydrogen peroxide with good enantioselectivity (ee up to $85 \%$ ) [70]. The reaction was found remarkable since the oxidation can be performed in open reaction vessels (atmospheric oxygen and water do not affect the outcome) and only $0.01 \mathrm{~mol} \%$ of the catalyst was necessary. Similar ligands were modified by introducing a second element of chirality in the salicylic aldehyde moiety to give enantiomeric excesses up to $78 \%$ ee for the sulfoxidation of thioanisole [71]. Schiff base ligands possessing various 1,1'-binaphtyl units were also tested as efficient chiral auxiliaries in the presence of vanadium complex [72]. High enantioselectivity (up to 93\% ee) was observed with acceptable chemical yield. Two librairies of chiral Schiff base ligands were synthesized by Anson and coworkers [73] for the optimization of Bolm's protocol [70]. Some of the vanadium complexes were found highly enantioselective and optically active sulfoxides were obtained in good yields with up to $97 \%$ ee. Other recent investigations on this Bolm catalytic system have mainly focused on structural modification of chiral Schiff bases [74-78], using of chlorine dioxide as oxidant [79] or portionwise addition of $\mathrm{H}_{2} \mathrm{O}_{2}$ [80]. Sulfoxidation and concomitant efficient kinetic resolution of sulfoxides was also reported with vanadium-salan system [81] and vanadium-Schiff base complexes [82, 83].

The first example of the catalytic asymmetric oxidation of tert-butyl disulfide giving tert-butyl tert-butanethiosulfinate (Scheme 5) obtained with 91\% enantiomeric excess in yields of $92 \%$ was described by Ellman and co-workers [84, 85]. The application of $\mathrm{H}_{2} \mathrm{O}_{2}$ as stoichiometric oxidant in the presence of $0.25 \mathrm{~mol} \%$ of $\mathrm{VO}(\mathrm{acac})_{2}$ and $0.26 \mathrm{~mol} \%$ of a chiral Schiff base ligand was found both convenient and cost-effective. A facile and selective method for the bis(arylthio)alkanes into $\mathrm{C} 2$ symmetric chiral sulfoxide transformation was also described by Skarzewski and co-workers [86]. The two-phase oxidation of bis-sulfides with hydrogen peroxide catalyzed by vanadium complex of chiral Schiff base leads to the 
corresponding chiral mono- and bis-sulfoxides. In the case of 1,2-bis(arylthio)ethanes the respective optically active bis-sulfoxides are formed in up to over 95\% ee [86].

Despite extensive studies on the catalytic system first reported by Bolm in 1995 [70], only few papers [87-89] report crystal structures of oxovanadium(V) complexes of Schiff bases of chiral amino alcohols. However, recently, the first example on crystal and molecular structure of oxido-bridged dinuclear vanadium(V) complex incorporating tridentate Schiff base ligand derived from chiral amino alcohol was reported by Romanovski and Lys [90].

\subsection{Niobium catalysts}

Miyazaki and Katsuki reported the first asymmetric sulfoxidation with urea-hydrogen peroxide catalyzed by niobium [91]. Using niobium(salen) complex, the oxidation of aryl alkyl sulfides and benzyl methyl sulfide showed good enantioselectivity under optimized conditions (ee up to 86\%). Possible oxidation of niobium(III) to niobium(V) during complex formation was suggested based on mass spectrometry analysis.

\subsection{Titanium catalysts}

Asymmetric oxidation of sulfides catalyzed by titanium complexes in the synthesis of biologically active sulfoxides has been reported as a review in 2009 [69] and also, as chapter in reviews [20, 22]. Since the pioneering works of Kagan [15] and Modena [16] who described enantioselective sulfoxidation with alkyl hydroperoxides using titanium tartrate catalysts, a wide variety of other chiral titanium complexes has been applied in this reaction, some of the catalytic systems using hydrogen peroxide as oxidant. In 2001, Katsuki and coworkers [92, 93] developed a highly enantioselective oxidation of sulfides using Ti(salen) complex as catalyst and urea-hydrogen peroxide as the oxidant. Asymmetric oxidation of 2substituted 1,3-dithianes using a $\operatorname{Ti}($ salen) and urea-hydrogen peroxide system in methanol was found to proceed with high enantioselectivity to give the corresponding mono-sulfoxides $[94,95]$. In these system, a di- $\mu$-oxo Ti(salen) complex, prepared by treatment of $\mathrm{Ti}(\mathrm{salen}) \mathrm{Cl}_{2}$ with water and triethylamine, was used as the catalyst (Scheme 6).

Sulfoxidation catalysts generated in situ from titanium(IV) isopropoxide and enantiopure Schiff bases promote the enantioselective oxidation of alkyl aryl sulfides to the corresponding sulfoxides at low catalyst loading $(<1 \mathrm{~mol} \%), 30 \%$ aqueous hydrogen peroxide being the terminal oxidant [96]. Upon screening of several ligands derived from aminoalcohols and 
salicylaldehydes, a catalyst affording sulfoxides with over $90 \%$ chemoselectivity and up to $60 \%$ ee was found, and the kinetic of the catalytic reaction was analyzed by ${ }^{1} \mathrm{H}$ NMR.

Asymmetric oxidation of sulfides to sulfoxides by aqueous hydrogen peroxide with catalysis by titanium-salan complexes was reported by Bryliakov and Talsi [97]. Optically active sulfoxides have been obtained with good to high enantioselectivities (up to 97\% ee) by a tandem enantioselective oxidation and kinetic resolution procedure, the catalyst performing over 500 turnovers with no loss of enantioselectivity.

For eventual in situ preparation of chiral $(R)$-menthyloxycarbonyl-1,2-dihydroisoquinolin1-yl) hydroperoxides and their application in stereoselective O-transfer reactions, isoquinolines were combined with $(R)$-menthyl chloroformate, hydrogen peroxide and metal alkoxides [98]. These mixtures allowed a stereoselective synthesis of aryl methyl sulfoxides from corresponding sulfides. The stereoselectivity results from a kinetic resolution of racemic sulfoxides formed in the first step wherein the $(S)$-enantiomer was faster oxidized to the corresponding sulfone [98]. However, only low enantioselectivities were achieved with this system (ee up to $23 \%$ ) with a large amount of sulfone (19\%).

Bryliakov and Talsi reported a simple and efficient catalytic procedure for the oxidation of bulky thioethers with hydrogen peroxide $[99,100]$. This has been achieved by reducing the steric bulk of the salicylidene rings [100].

Asymmetric sulfoxidation of thioanisole by helical Ti(IV) salan catalysts has been recently developed [101]. Complexation of these flexible ligands to $\mathrm{TiCl}_{4}$ produced $\mathrm{TiCl}_{2}$ (salan) complexes which were tested for the asymmetric sulfoxidation of thioanisole with hydrogen peroxide as oxidant (ee up to $43 \%$ ). New Ti-salan complexes were also applied as catalysts in the sulfoxidation of thioanisole with $\mathrm{H}_{2} \mathrm{O}_{2}$ in dichloroethane [102]. They showed high activities but only moderate enantioselectivities (ee up to 51\%). For greener catalysis purpose, these complexes were also tested in selected ionic liquids with hydrogen peroxide as oxidant but with reduced induced asymmetry (ee up to $18 \%$ ).

Very recently, an efficient asymmetric oxidation of prochiral sulfides catalyzed by a series of simple in situ generated complexes based on chiral amino alcohol derived Schiff bases with $\mathrm{Ti}(\mathrm{Oi}-\mathrm{Pr}) 4$ was carried out in presence of $\mathrm{H}_{2} \mathrm{O}_{2}$ at $0^{\circ} \mathrm{C}$ [103]. Prochiral sulfides were converted to respective chiral sulfoxides efficiently (93\% conversion, up to $98 \%$ ee) with this system. 


\subsection{Platinum catalysts}

Stereoselective sulfoxidation of prochiral aryl alkyl sulfides to the corresponding sulfoxides can be achieved in water-surfactant medium with hydrogen peroxide catalyzed by chiral platinum diphosphine complex (Figure 7) with ee up to 88\% [104]. A remarkable key feature was the easy isolation of the products by simple diethyl ether/water-surfactant twophase separation.

\subsection{Copper catalysts}

Copper has received some attention in metal-catalyzed asymmetric oxidation, using hydrogen peroxide as oxidant [75,105] but with moderate ee and low yields. More recently, copper Schiff base mediated asymmetric oxidation of aryl benzyl sulfides has been reported by Maguire et al. [106]. These results compare favourably to other known copper mediated asymmetric sulfide oxidation methods, especially in term of enantiocontrol (up to $81 \%$ ee), but yields and overall enantioselectivities are modest compared to other available methods. The method is similar to the vanadium and iron Schiff base mediated oxidations reported by Bolm in that the same oxidant and ligands are employed. Expansion of this investigation resulted in improved yields, while retaining good enantioselectivity through variation of reaction conditions, such as the nature of the solvent and small change in ligand structure [107].

\subsection{Aluminum catalysts}

Katsuki and co-workers [108] first discovered that treatment of $\mathrm{Al}$ (salalen) complexes with water provided new-water compatible complexes which can be used as catalysts under aqueous conditions for asymmetric sulfoxidation reactions. Later, the same group [109, 110] has reported that aluminum-(salalen) complex (Figure 8) is an effective catalyst for asymmetric oxidation of sulfur compounds such as acyclic and cyclic sulfides in the presence of aqueous hydrogen peroxide as the stoichiometric oxidant. This work has been extended to asymmetric oxidation of cyclic dithioacetals with high diastereo- and enantioselectivity [111].

\subsection{Tungsten catalysts}

The use of heterogeneous catalysts under ambient conditions offers several advantages compared with their homogeneous counterparts e.g. ease of recovery and recycling and 
enhanced stability. New heterogeneous catalysts with tungsten-based system have been reported using hydrogen peroxide as oxidant. Thus $\mathrm{WO}_{3}$-catalyzed asymmetric oxidation of thioethers and kinetic resolution of sulfoxides with $30 \%$ aq. $\mathrm{H}_{2} \mathrm{O}_{2}$ in the presence of cinchona alkaloids under heterogeneous conditions affords chiral sulfoxides in high yields with moderate to good enantioselectivities (ee up to 90\%) [112]. The asymmetric oxidation of sulfides catalyzed by $\mathrm{WO}_{3}$ and $\mathrm{H}_{2} \mathrm{O}_{2}$ in the presence of salan as chiral ligands under heterogeneous conditions has been also reported but with moderate enantioselectivities (ee max: 67\%) [113]. The synthesis and characterization of new chiral polyoxotungstophosphonates, in enantiopure form, derived from the covalent functionalization of lacunary Keggin-type precursors has been more recently reported [114]. The resulting complexes display high hydrolytic stability but, unfortunately, very low enantioselectivity (ee $<10 \%$ ) as catalysts in sulfoxidation reactions, in combination with hydrogen peroxide as bulk oxidant. Although these preliminary catalytic results are of limited synthetic interest, the oxidative activity and stability of these tungsten-based systems offer a starting point for the development of novel stereoselective heterogeneous catalysts.

A summary of selected asymmetric sulfoxidations so far showing the best enantioselectivity is given in the Table 1. Thus, several catalytic systems based on vanadium (Bolm), iron (Bolm, Katsuki, Simonneaux), aluminium (Katsuki), titanium (Bryliakov) which have been discovered within the last 15 years, employ $\mathrm{H}_{2} \mathrm{O}_{2}$, affording sulfoxides with high selectivities and with ee up to $98 \%$, performing large turnovers and demonstrating good oxidant economies. It is also noteworthy that a number of important chiral sulfoxides and biologically active compounds are already prepared by the use of metal catalysts with high yield and enantioselectivity. However, there are still many challenging areas for future research. First, new systems are necessary for oxidation of molecules containing highly reactive groups such as carbonyl, hydroxyl and unsaturated groups. There is also a great need for discovering alternative systems which are less destructive to the chiral ligands. Design and synthesis of simpler porphyrin and non-porphyrin chiral ligands are still an urging need.

\section{Asymmetric epoxidation of alkenes}

Catalytic asymmetric epoxidation reactions play a major role in organic chemistry since the optically active epoxides are important building blocks $[1,115,116]$. In particular, catalytic asymmetric reactions in aqueous solutions are attractive, but rare [7]. Therefore until 2006, results obtained in the asymmetric epoxidation with $\mathrm{H}_{2} \mathrm{O}_{2}$ and chiral metal catalysts 
have been rather disappointing [5]. It is only quite recently, however, that the metal-catalyzed asymmetric epoxidation of aromatic alkenes with hydrogen peroxide as the oxygen source and various chiral ligands has been reported, as a nice possibility (vide infra), using for example, metal-binding combinatorial libraries for the discovery of new catalysts [117]. Chiral epoxy alcohols are also interesting building blocks for organic synthesis and consequently, asymmetric epoxidation of allylic alcohols has been largely developed. As a remarkable example, Katsuki and Sharpless reported in 1980, a highly enantioselective epoxidation of allylic alcohols using a titanium/tartrate/t-butyl hydroperoxide system [118]. Later, several other stereoselective systems were reported using chiral vanadium complexes as catalysts [119-122]. However, all these methods require the use of alkyl hydroperoxide as the oxidant. Asymmetric catalysis of epoxidation of allylic alcohols using hydrogen peroxide by niobium-salan complexes was recently discovered by the group of Katsuki [123, 124] (vide infra).

Epoxidation catalyzed by non-heme iron and manganese complexes has been reviewed in 2012 [125]. There are also several reviews on oxidation catalyzed by metalloporphyrins [4, 126-128].

\subsection{Iron systems}

\subsection{1 non-heme systems}

Environmentally benign epoxidation protocols are an important challenge in organic chemistry and catalysis. In this regard, iron complexes are ideal catalysts owing to their availability, cost, and toxicity. Jacobsen et al. [129] have found Fe(II)(mep) (mep: N,N'dimethyl-N,N'-bis(2-pyridylmethyl)-ethane,1,2-diamine) with $\mathrm{SbF}_{6}^{-}$counterions to be an efficient epoxidation catalyst with $\mathrm{H}_{2} \mathrm{O}_{2}$ in the presence of acetic acid ( $\left.\mathrm{AcOH}\right)$. A novel and general biomimetic non-heme Fe-catalyzed asymmetric epoxidation of aromatic alkenes by using hydrogen peroxide was reported by Beller and co-workers [130, 131]. The catalyst consists of ferric chloride hexahydrate $\left(\mathrm{FeCl}_{3}, 6 \mathrm{H}_{2} \mathrm{O}\right)$, pyridine-2,6-dicarboxylic acid, and readily accessible chiral $\mathrm{N}$-arenesulfonyl-N'-benzyl-substituted ethylenediamine ligands (Scheme 7). The asymmetric epoxidation of styrene with this system gave high conversions but moderate enantiomeric excesses, whereas larger alkenes gave high conversions and ee values.

Recently the enantioselective epoxidation of several alkenes, including terminal ones, has been realized by using new iron(III) complexes, generated in situ from primary aminederived non-symmetrical Schiff base ligands and aqueous $\mathrm{H}_{2} \mathrm{O}_{2}$ as environmentally benign 
oxidant [33]. In case of trans-stilbene and derivatives, yields of up to $84 \%$ and ee values of up to $30 \%$ were obtained. Another system, using chiral bipyrrolidine based iron and manganese complexes $\left[((\mathrm{S}, \mathrm{S})-\mathrm{pdp}) \mathrm{M}(\mathrm{II})(\mathrm{OTf})_{2}\right]$ (Scheme 8) catalyzes the asymmetric epoxidation of various olefins with $\mathrm{H}_{2} \mathrm{O}_{2}$ in the presence of carboxylic acid additives with high efficiency (up to 1000 turnover number (TON)) and selectivity (up to 100\%), and with good to high enantioselectivity (up to $87 \%$ enantiomeric excess) (Scheme 8) [132]. The enantioselectivity increases with growing steric demand of the acid. On the basis of the electron paramagnetic resonance (EPR) spectroscopy and enantioselectivity studies, the active oxygen-transferring species of the above systems can be identified as structurally similar oxometal(V) species of the type $[((\mathrm{S}, \mathrm{S})-\mathrm{pdp}) \mathrm{M}(\mathrm{V})=\mathrm{O}(\mathrm{OCOR})]_{2}{ }^{+}(\mathrm{M}=\mathrm{Fe}, \mathrm{Mn} ; \mathrm{R}=$ alkyl $)[132]$.

Chiral bioinspired iron complexes of N4 ligands based on the ethylenediamine backbone (Figure 9) display remarkable levels of enantioselectivity for the first time in the asymmetric epoxidation of $\alpha, \beta$-unsaturated ketones using hydrogen peroxide (up to $87 \%$ ee) as oxidant [133]. Notably, isotopic labeling with $\mathrm{H}_{2}{ }^{18} \mathrm{O}$ strongly demonstrated that there is a reversible water binding step prior to generation of the significant intermediate. In addition, the possible mechanisms were proposed and $\mathrm{LFe}(\mathrm{V})=\mathrm{O}$ species may be the main active intermediates in the catalytic system [133].

\subsubsection{Iron porphyrins}

The discovery that hydrogen peroxide supports catalytic turnover of cytochrome P-450 in the absence of electron transfer proteins or cosubstrates has been important for mechanistic studies of this enzyme [134]. In particular, it was proposed that P-450's ability to utilize peroxides in place of dioxygen and $\mathrm{NAD}(\mathrm{P}) \mathrm{H}$ to drive hydroxylation via the peroxide shunt pathway could provide a way to confront the cofactor regeneration problem $[135,136]$. However, generally, the efficiency of this reaction is poor compared with that of reductive activation of molecular oxygen. It should be also noted that there are cytochromes P-450s, which can be classified as a $\mathrm{H}_{2} \mathrm{O}_{2}$-dependent P-450s [137,138]. Due to the obvious relevance of cytochrome P-450 mechanism, catalytic epoxidation by iron porphyrins has drawn particular attention $[4,128,139]$. Since the discovery of iron porphyrin catalyzed epoxidation and hydroxylation [140], the first asymmetric epoxidation catalyzed by chiral porphyrins was reported by Groves and Myers in 1983 [141]. Since then, different chiral iron porphyrins were used by the same group [42] and others [47,128,142-147]. The oxidant of choice for these systems is generally iodosylbenzene. Some examples of the use of hydrogen peroxide can be 
found in the literature with iron porphyrins as catalysts [48, 50, 148, 149], but no reports of enantioselectivity [116]. It is only recently that chiral epoxidation of alkenes and hydroxylation of alkanes using $\mathrm{H}_{2} \mathrm{O}_{2}$ as oxidant has been successfully catalyzed by optically active water-soluble iron porphyrin (Figure 3) [150]. The asymmetric epoxidation of styrene derivatives by $\mathrm{H}_{2} \mathrm{O}_{2}$ (or UHP) to give optically active epoxides (ee up to 81\%) was carried out in methanol and water using chiral water-soluble iron porphyrins as catalysts (Figure 3).

\subsection{Ruthenium catalysts}

The first asymmetric epoxidation catalyzed by a ruthenium complex (Scheme 9) that exploits hydrogen peroxide as the primary oxidant was reported in 1999 by Stoop and Mezzetti [151]. Up to $42 \%$ ee was obtained in the asymmetric epoxidation of styrene and other unfunctionalized olefins catalyzed by ruthenium Schiff based complex $[\mathrm{RuCl}(\mathrm{PNNP})] \mathrm{PF}_{6}(\mathrm{PNNP}=\mathrm{N}, \mathrm{N}-\{$ bis $(o$-diphenylphosphino $)$ benzylidene $\}$-(1S,2S)-diiminocyclohexane using hydrogen peroxide as the primary oxidant [152].

A more general ruthenium catalyzed asymmetric epoxidation procedure of olefins using $\mathrm{H}_{2} \mathrm{O}_{2}$ has been developed by Beller and co-workers [153]. Using new pyboxazine type ligands (Scheme 10), enantioselectivies (generally 50-80\%) up to $84 \%$ were observed for different aromatic olefins [153]. Using a different ruthenium complex, first introduced by Nishiyama and co-workers [154], the same group also succeeded asymmetric epoxidation with $\mathrm{H}_{2} \mathrm{O}_{2}$ but with less enantioselectivities (ee< 30\%) [155].

A small ligand library of chiral tridentate N,N,N-pyridinebisimidazolines have been synthesized for the first time by Beller and co-workers (Scheme 11) [156]. This new class of ligands can be easily tuned and synthesized on multi g-scale. The usefulness of the ligands is shown in the ruthenium-catalyzed asymmetric epoxidation with hydrogen peroxide as oxidant. Excellent yields (>99\%) and good enantioselectivities (up to $71 \%$ ee) have been obtained for the epoxidation of aromatic olefins [156].

\subsection{Manganese systems}

\subsubsection{Non-porphyrinic manganese systems}

The groups of Jacobsen [157-159] and Katsuki [160,161] pioneered the manganesesalen-catalyzed enantioselective oxidation of unfunctionalized olefins. In these systems, oxygen transfer to the olefin is realized by $\mathrm{C}_{2}$-symmetric manganese(III)-salen type complex, using generally iodosoarenes or hypochlorite as terminal oxidants. However, hydrogen 
peroxide was found to serve as an effective terminal oxidant for the salen-catalyzed asymmetric epoxidation of chromene derivatives (Scheme 12) [162] or 1,2-dihydronaphtalene [163], when N-methylimidazole was added to the reaction medium. Hydrogen peroxide has also been applied for a series of seven chiral pentadentate dihydrosalen ligands (Figure 10), carrying an imidazole group as a fifth, axial donor [164, 165]. These ligands were synthesized in racemic and enantiomerically pure form. All of these ligands afforded mononuclear manganese(III) complexes in good yields. The complexes catalyzed the epoxidation of olefins with a variety of terminal oxidants, but most importantly, with dilute (1\%) aqueous hydrogen peroxide and without any added co-ligands. With 1,2dihydronaphthalene as substrate and 10 mol\% of catalyst, enantiomeric excesses up to $66 \%$ were achieved in 1996 . This value was the highest at this time reported for an asymmetric epoxidation of 1,2-dihydronaphthalene, using hydrogen peroxide as oxidant and a salen-type complex as catalyst.

Chiral manganese complexes bearing optically active 1,4,7-triazacyclononanes were also able to catalyze the asymmetric oxidation of unfunctionalized olefins with hydrogen peroxide to give optically active epoxides with ees up to $43 \%$ but the conversion was quite low [166].

Two dinuclear manganese complexes containing enantiomerically pure $(R)$ - and $(S)-1$ (2-hydroxypropyl)-4,7-dimethyl-1,4,7-triazacyclononane $(S, S-1, R, R-1)$ ligands have been isolated as the hexafluorophosphate salts [167]. The enantiomeric complexes $S, S-1$ and $R, R-1$ were found to catalyze the oxidation of olefins, alkanes, and alcohols with hydrogen peroxide. In the epoxidation of indene, the enantiomeric excess values attain $13 \%$.

A series of chiral tetradentate $\mathrm{N}_{4}$ ligands together with their manganese complexes have been designed and synthesized by Sun and coworkers (Scheme 13) [168]. Nice results were obtained with $1 \mathrm{~mol} \%$ catalyst loading, since the enantioselective epoxidation of olefins proceeds with nearly full conversion and enantiomeric excess values up to $89 \%$.

The enantioselective epoxidation of 6-cyano-2,2-dimethylchromene (Chrom) catalyzed by the Jacobsen catalyst, using sodium hypochlorite $(\mathrm{NaOCl})$ as oxygen source, at room temperature, was performed in a series of 1,3-dialkylimidazolium and tetra-alkyldimethylguanidium based ionic liquids [169]. Other oxygen sources, such as iodosylbenzene, hydrogen peroxide and urea-hydrogen peroxide adduct, were also tested but the best results were achieved with $\mathrm{NaOCl}$.

Chiral non-heme aminopyridine manganese complexes (Figure 11) catalyze the enantioselective epoxidation of olefins with peracetic acid or hydrogen peroxide with 
moderate to high yields and ee values up to $89 \%$ (peracetic acid, $\mathrm{AcOOH}$ ) and $84 \%$, performing as many as 1000 turnovers [170].

Chiral bipyrrolidine based iron manganese complexes [((S,S)-pdp)M(II)(OTf $\left.)_{2}\right]$ catalyze the asymmetric epoxidation of various olefins with $\mathrm{H}_{2} \mathrm{O}_{2}$ in the presence of carboxylic acid additives with high efficiency (up to 1000 turnover number (TON)) and selectivity (up to 100\%), and with good to high enantioselectivity (up to $93 \%$ enantiomeric excess. The enantioselectivity increases with growing steric demand of the acid (vide supra, Scheme 8) [132]. New ternary immobilization of chiral sulfonato-(salen)manganese(III) complex for aqueous asymmetric epoxidation reactions was also reported by Sun and coworkers [59].

Organic carbonates, e.g., dimethyl carbonate and propylene carbonate were used as reaction media in enantioselective epoxidation of non-functionalized alkenes by using a series of chiral macrocyclic $\mathrm{Mn}(\mathrm{III})$ salen complexes (5 mol\%) as catalyst with pyridine $\mathrm{N}$-oxide as oxidant [171]. This protocol worked effectively with urea hydrogen peroxide, as well as sodium hypochlorite as oxidants to give respective epoxides in high yields and ee (up to $>91 \%)[171]$.

\subsubsection{Manganese porphyrin}

A few examples of the use of hydrogen peroxide can be found in the literature with manganese porphyrins as catalysts (Figure 12) giving low enantiomeric excess for epoxidation reaction in organic solvents or in biphasic medium [172, 173], if we except one example for epoxidation of 1,2-dihydronaphtalene (ee up to 60\%) [174]. It is only very recently that the asymmetric epoxidation of alkene derivatives by $\mathrm{H}_{2} \mathrm{O}_{2}$ to give optically active epoxides (ee up to 68\%), was carried out in water/methanol solutions using a chiral water-soluble manganese porphyrin as catalyst [175]. Various factors affecting the catalytic epoxidation of olefins were extensively investigated. Thus, it was recognized that the presence of water in methanol can be quite successful. Moreover working in basic buffered solutions also deeply increases the efficiency of the system. Only a small excess of oxidant versus alkene was necessary for these reactions [175]. It has been also demonstrated that the benign $\mathrm{H}_{2} \mathrm{O}_{2} / \mathrm{NaHCO}_{3}$ oxidative combination can be used for the enantioselective epoxidation of olefins using a chiral manganese porphyrin as a catalyst [176]. This unprecedented result was made possible by the use of an ionic liquid with ultrasound, which leads to the activation of Mn-porphyrin catalysis but the enantioselectivity of the epoxidation was moderate (maximum ee: $40 \%$ ) [176]. 


\subsection{Scandium catalysts}

A simple and $\mathrm{H}_{2} \mathrm{O}_{2}$-efficient asymmetric epoxidation of $\alpha, \beta$-unsaturated carbonyl compounds was accomplished using a chiral N,N'-dioxide-Sc(III) complex catalyst [177]. A number of optically active epoxides were obtained from the corresponding $\alpha, \beta$-unsaturated ketones and $\alpha, \beta$-unsaturated amides under additive-free conditions. The catalytic system is convenient with good water- and air-tolerance, as well as excellent yields and enantioselectivities [177].

\subsection{Niobium catalysts}

A dimeric $\mu$-oxo $\mathrm{Nb}$ (salan) complex was found to catalyze the asymmetric epoxidation of allylic alcohols using urea-hydrogen peroxide adduct as an oxidant with good enantioselectivity [123]. Subsequent studies indicated that the $\mu$-oxo dissociates into a monomeric species prior to epoxidation [124]. These monomeric complexes catalyze the epoxidation of allylic alcohols using hydrogen peroxide with hig enantioselectivity ranging from 83 to $95 \%$ ee. This was reported as the first example of the highly enantioselective epoxidation of allylic alcohols using aqueous hydrogen peroxide as oxidant [124]. In some cases, the resulting epoxy alcohols were partially oxidized under the experimental conditions to the corresponding epoxy aldehydes (10-20\%).

\subsection{Titanium catalysts}

In 1980, Katsuki and Sharpless reported the discovery of the first practical method for epoxidation [118]. It was the titanium-tartrate catalyzed asymmetric epoxidation of allylic alcohols by tert-butyl hydroperoxide. However, this stoichiometric oxidant generates a large amount of materials and a more highly atom-efficient is recommended and fortunately, oxidants other than tert-butyl hydroperoxide can also be used in the asymmetric epoxidation. Thus asymmetric epoxidation catalyzed by Ti(salalen) complexes (Scheme 14) $[178,179]$ and Ti(salan) (Scheme 15) [179-181] was developed by Katsuki group using aqueous hydrogen peroxide as the oxidant. In the presence of $\mathrm{pH} 7.4$ phosphate buffer, the reaction of various conjugate olefins proceeded smoothly to afford the corresponding epoxides in high yield with high enantioselectivity. Bis- $\mu$-oxo-bridged binuclear Ti-salan catalysts have also been found 
to catalyze enantioselective epoxidation of olefins with $\mathrm{H}_{2} \mathrm{O}_{2}$ as the oxidant, demonstrating moderate to high enantioselectivities (55-98\% ee values) $[179,180]$.

Titanium(salalen) complex was also an effective catalyst for asymmetric epoxidation of enol esters. Although (E)-enol esters were reluctant to proceed, (Z)-enol esters underwent asymmetric epoxidation to give the epoxides in high yields with high enantioselectivity ranging from 86 to $>99 \%$ ee in the presence of aqueous hydrogen peroxide as the stoichiometric oxidant [182]. The obtained epoxides were transformed into the corresponding 1,2-diols with no erosion of high enantiomeric excess.

\subsection{Platinum catalysts}

$\left.\left[\mathrm{P}_{2} * \operatorname{Pt}\left(\mathrm{CF}_{3}\right)\left(\mathrm{CH}_{2} \mathrm{Cl}_{2}\right)\right] \mathrm{BF}_{3}\right)\left(\mathrm{P}_{2} *=\right.$ chiraphos, prophos, diop; $\left.\mathrm{X}=\mathrm{C} 1, \mathrm{OH}\right)$ cationic solvato complexes have been used as catalysts in the epoxidation of 1-octene and propene with diluted hydrogen peroxide (Scheme 16) [183]. The obtained epoxides are optically active with enantiomeric excess (ee) as high as $41 \%$. Remarkable improvements in enantioselectivity as well as recycle were also observed in the catalytic asymmetric epoxidation of terminal alkenes with a chiral, electron-poor platinum(II) catalyst with hydrogen peroxide as terminal oxidant in water-surfactant media [184].

\subsection{Copper catalysts}

Chiral copper proline diamide complex has been immobilized on surface of mesoporous silica [185]. These heterogenized complex catalysts were examined as asymmetric catalysts for the epoxidation of $\alpha, \beta$-unsaturated carbonyl compounds with hydrogen peroxide, tertbutyl hydroperoxide and urea hydroperoxide as the oxidants under solvent-free condition. Enantiomeric excesses of up to $84 \%$ can be achieved conveniently with a good conversion using these promising catalysts [185]. Interestingly, the recycled catalyst worked well up to five catalytic runs with marginal loss in yield.

\subsection{Rhenium catalysts}

An impressive amount of work has been carried out on the catalytic properties of methyltrioxorhenium(VII) (MTO) and more specifically on its possibilities as a selective epoxidation catalyst using $\mathrm{H}_{2} \mathrm{O}_{2}$ as oxidant [186,187]. A review reported in 2005 described the different attempts to succeed enantioselective epoxidation catalyzed by rhenium and 
molybdenum systems [188]. It was expected that the organometallic methyltrioxorhenium compound could be transformed into chiral epoxidation catalyst by adding chiral Lewis base ligands. One of the first attempts to utilize chiral N-base adducts of MTO as catalysts in chiral epoxidation was made by Corma et al. [189]. Unfortunately, the enantiomeric excess and the conversion were quite low (both inferior to 35\%). Methyltrioxorhenium(VII) (MTO) was also successfully applied as chiral epoxidation catalysts in the presence of $\mathrm{H}_{2} \mathrm{O}_{2}$ as oxidizing reagent and excess chiral Lewis base ligands derived from pyrazole [190]. These chiral Lewis base ligands allow to obtain moderate enantiomeric excesses (ee up to 41\%), which are however, associated with generally low overall conversions $(<30 \%)$. Recently, several bidentate $\mathrm{N}$-donor benzimidazolic adducts of MTO were synthesized and applied for catalytic olefin epoxidation using $\mathrm{H}_{2} \mathrm{O}_{2}$ as oxidant in $\mathrm{CH}_{2} \mathrm{Cl}_{2}$ at room temperature [191]. Since a major drawback of the rhenium system with hydrogen peroxide is the Lewis acidity of the catalyst in the presence of water, chiral bidentate $\mathrm{N}$-donor benzimidazolic adducts may open new routes for asymmetric epoxidation.

In conclusion, the accomplishments achieved thus far in asymmetric catalytic epoxidation with hydrogen peroxide are impressive, but they are by no means complete. High enantiocontrol is characteristic of reactions with some alkene substrates but not styrene derivatives. A summary of selected asymmetric epoxidations so far showing the best enantioselectivity is given in the Table 2 . Long-term catalyst stability vs hydrogen peroxide has not received adequate attention and new asymmetric catalysts are required.

\section{Asymmetric dihydroxylation of alkenes}

The development of the osmium catalyzed asymmetric cis-dihydroxylation of alkenes by Sharpless and co-workers [192,193] has proven to be invaluable to synthetic organic chemistry. However, the cost and toxicity of the osmium based asymmetric cisdihydroxylation system, prevents their widespread industrial application. This has provided a strong driving force to the identification and development of economically viable and environmentally benign methods based on first row transition metals and $\mathrm{H}_{2} \mathrm{O}_{2}[194,195]$.

\subsection{Iron catalysts}

The first example of iron-catalyzed asymmetric cis-dihydroxylation of olefins was reported in 2001 by Que and co-workers (ee up to 82\%) [196]. The objective was to develop synthetic catalysts that model Rieske dioxygenases, which are bacterial enzymes, as a 
potential green alternative to traditional heavy metal reagents such as $\mathrm{OsO}_{4}$ and $\mathrm{RuO}_{4}$ [193]. These compounds are effective but less desirable due to their toxicity. More recently, ironcatalyzed asymmetric olefin cis-dihydroxylation has been recently reported with $97 \%$ enantiomeric excess [197]. The optically active ligands used in these reactions are shown in Figure 14.

\subsection{Manganese catalysts}

High turnover enantioselective alkene cis-dihydroxylation with $\mathrm{H}_{2} \mathrm{O}_{2}$ catalyzed by manganese based complexes containing chiral carboxylato ligands was reported for the first time by Feringa and co-workers [198,199]. With 0.4 mol\% catalyst loading the enantioselective cis-dihydroxylation of 2,2-dimethylchromene (Scheme 17) proceeds with full conversion and high selectivity towards the cis-diol product with enantiomeric excess of up to $54 \%$ and with high turnover. Selected homogeneous manganese catalytic systems, including 'ligand free' and pyridyl amine ligand based systems, that have been applied to alkene dihydroxylation and epoxidation have been recently reviewed [200].

\subsection{Osmium catalysts}

Although the Sharpless dihydroxylation of olefins with osmium tetraoxide has been used for several decades, osmium-catalyzed cis-dihydroxylation using $\mathrm{H}_{2} \mathrm{O}_{2}$ as oxidant is still rare. Selective cis-dihydroxylation of olefins with the aid of a triple catalytic system using $\mathrm{H}_{2} \mathrm{O}_{2}$ as the terminal oxidant has been developed [195]. In this process Os(VI) is recycled to Os(VIII) by a coupled electron transfer-mediator system based on $\mathrm{N}$-methylmorpholine and a biomimetic flavin, leading to a mild and selective electron transfer. Aliphatic, aromatic, and functionalized olefins were successfully cis-dihydroxylated, employing the triple catalytic system. The present biomimetic catalytic system works well in asymmetric dihydroxylation and gave optically active diols in good isolated yields and high enantiomeric excesses (up to 99\% ee) [195]. A trifunctional catalyst for one-pot synthesis of chiral diols via Heck coupling$\mathrm{N}$-oxidation-asymmetric dihydroxylation was also described by Choudary and co-workers [201]. The system was applied to the synthesis of diltiazem and taxol side chain. An improved process has been developed for the osmium-catalyzed dihydroxylation of olefins via in situ formation of $\mathrm{N}$-methylmorpholine-N-oxide from $\mathrm{N}$-methylmorpholine using $\mathrm{CO}_{2}$ catalysis and $\mathrm{H}_{2} \mathrm{O}_{2}$ [194]. All olefins examined were selectively cis-dihydroxylated to their corresponding diols in good to excellent yields, and by the use of chiral ligands, high enantiomeric excesses were obtained. A mechanism for the catalytic dihydroxylation of alkenes using hydrogen peroxide and osmium complexes has been recently proposed [202]. 


\section{Asymmetric hydroxylation of alkanes}

The functionalization of $\mathrm{C}-\mathrm{H}$ bonds of alkanes is one of the most difficult transformation in synthetic chemistry [203-205]. Nevertheless, these reactions are catalyzed by a variety of metalloenzymes, among which the most diverse are the many members of the cytochrome P450 family [206]. Thus the extracellular heme-thiolate peroxygenase from Agrocybe aegerita has been shown to hydroxylate alkanes and numerous other substrates using hydrogen peroxide as the terminal oxidant $[207,208]$. However the inert nature of non-activated C-H bonds generates large difficulties related to selectivity and enantioselectivity. Thus very few systems affording optically active alcohols using hydrogen peroxide as oxidant have been reported. This is true for non-heme systems and metalloporphyrin systems. They will be presented separately.

\subsection{Non-heme system}

Several bioinspired non-heme iron systems have been reported as attractive because they use hydrogen peroxide as oxidant. There is a recent review on this topic [125]. Thus various examples of alkane hydroxylations with hydrogen peroxide, catalyzed by non-heme iron complexes with polydentate $\mathrm{N}$-donor ligands, have been reported since early 1990s but without any enantioselectivity. In contrast, the hydroxylation of alkanes by hydrogen peroxide catalyzed by a chiral $\mu$-oxo diferric complex (Scheme 18) has been demonstrated by Fontecave et al. [209] to be stereospecific and partially enantioselective indicating a metalbased mechanism. However, low enantiomeric excess was obtained with this system (up to 15 $\%)$.

\subsection{Iron and manganese porphyrins}

Selective functionalization of saturated $\mathrm{C}-\mathrm{H}$ bonds with metalloporphyrin catalysts has been reviewed recently by Che [204] and Zhang [205]. Among the metalloporphyrincatalyzed reactions highlighted herein are the hydroxylation of steroids, cycloalkanes and benzylic hydrocarbons. Since the discovery of iron porphyrin catalyzed hydroxylation [140], Groves and Viski [42, 210] reported the first enantioselective hydroxylation catalyzed by a metalloporphyrin, with up to $40 \%$ ee obtained from hydroxylation of ethylbenzene by $\mathrm{PhIO}$ using a chiral iron (III) porphyrin catalyst. When manganese was used as a metal, higher product yields were obtained, but with lower enantioselectivities. Ketones were also observed as side products in the catalytic reactions. 
In 1999, Gross and Ini [211] reported the first example of ruthenium-catalyzed asymmetric hydroxylation of racemic alkanes and their kinetic resolution (ee up to 38\%), using D2-symmetric chiral porphyrin ligand and 2,6-dichlropyridine N-oxide as oxidant. Che and coworkers [212,213] reported the Ru-catalyzed enantioselective hydroxylation of aromatic hydrocarbons with benzylic $\mathrm{C}-\mathrm{H}$ bonds. Using $2,6-\mathrm{Cl}_{2} \mathrm{pyNO}$ as oxidant, the chiral ruthenium porphyrin was shown to be an effective catalyst for hydroxylating a series of aromatic hydrocarbons to form the corresponding secondary alcohols. Although conversions of the substrates were low, the Ru-based hydroxylation gave good yields and up to $76 \%$ ee.

The oxidant of choice for these systems is generally iodosylbenzene for iron and manganese catalysts, and dichloropyridine $\mathrm{N}$-oxide with ruthenium catalysts. Some examples of the use of hydrogen peroxide for hydroxylation of saturated $\mathrm{C}-\mathrm{H}$ bonds can be found in the literature with iron porphyrins as catalysts $[48,148]$ but, only one example reports of enantioselectivity with iron catalysts [150]. Thus the asymmetric hydroxylation of alkanes to give optically active secondary alcohols (ee up to 63\%) was carried out in methanol and water using a chiral water-soluble iron porphyrin as catalyst [150]. However, this reaction was limited to more reactive substrates such as indane and tetrahydronaphtalene. Other limitation is that the system needs an excess of alkene versus oxidant. Consequently, asymmetric hydroxylation of alkanes using hydrogen peroxide as oxidant is still difficult to proceed without electron-deficient chiral metalloporphyrins.

A few examples of the use of $\mathrm{H}_{2} \mathrm{O}_{2}$ can be found in the literature with manganese porphyrins as catalysts, giving low enantiomeric excess (ee) for epoxidation reaction in organic solvents or in a biphasic medium[173,174]. However, to our knowledge, there were no examples of asymmetric hydroxylation by hydrogen peroxide in water catalyzed by $\mathrm{Mn}$ porphyrins until Simonneaux and co-workers [175] recently reported the asymmetric hydroxylation of arylalkane derivatives by $\mathrm{H}_{2} \mathrm{O}_{2}$ to give optically active alcohols (ee up to $57 \%$ ). The reactions were carried out in water/methanol solutions using chiral water-soluble manganese porphyrins as catalysts and five equiv of oxidant versus alkane was necessary. However, further optimization of the reaction medium to increase the enantioselectivity, and more experiments to identify the precise role of chirality in the mechanism will be necessary. 


\section{Conclusion}

Most of the work presented herein indicates that the asymmetric oxidation using chiral metal complexes as catalysts and hydrogen peroxide as oxidant is possible, with good results. Diastereo- and enantioselectivities comparable to those obtained with different oxidants are observed in organic solvents and in water. This is true for sulfoxidation reaction and in a less extent for epoxidation reaction. Although the number of efficient systems is relatively high, their development must be widened in the future for asymmetric hydroxylation of alkanes with hydrogen peroxide which remains an outstanding challenge in catalysis. The use of chiral heterogeneous catalysts [214] under ambient conditions offers several advantages compared to their homogeneous counterparts, such as ease of recovery and recycling and enhanced stability. With regard to oxidation catalysis in presence of hydrogen peroxide, the resistance to degradation merits further work since this factor is usually determinant on catalytic activity and selectivity. 
References

[1] B.S. Lane, K. Burgess, Chem. Rev. 103 (2003) 2457-2474.

[2] S. Liao, I. Coric, Q. Wang, L. B., J. Am. Chem. Soc. 134 (2012) 10765-10768.

[3] R. Noyori, M. Aoki, K. Sato, Chem. Commun. (2003) 1977-1986.

[4] B. Meunier, Chem. Rev. 92 (1992) 1411-1456.

[5] I.W.C.E. Arends, Angew. Chem., Int. Ed. Engl. 45 (2006) 6250-6252.

[6] S. Juliá, J. Masana, J.C. Vega, Angew. Chem., Int. Ed. Engl. 19 (1980) 929-931.

[7] W. Zhuang, M. Marigo, K.A. Jorgensen, Org. Biomol.Chem. 3 (2005) 3883-3885.

[8] A. Russo, C. De Fusco, A. Lattanzi, ChemCatChem 4 (2012) 901-916.

[9] G.J. ten Brink, I.W.C.E. Arends, R.A. Sheldon, Chem. Rev. 104 (2004) 4105-4123.

[10] A. Gusso, C. Baccin, F. Pinna, G. Strukul, Organometallics 13 (1994) 3442-3451.

[11] G. Bianchini, A. Cavarzan, A. Scarzo, G. Strukul, Green Chem. 11 (2009) 1517-1520.

[12] A. Cavarzan, G. Bianchini, P. Sgarbossa, L. Lefort, S. Gladiali, A. Scarzo, G. Strukul, Chem. Eur. J. 15 (2009) 7930-7939.

[13] G. Strukul, Angew. Chem., Int. Ed. Engl. 37 (1998) 1198-1209.

[14] M. Rentz, B. Meunier, Eur. J. Org. Chem. (1999) 737-750.

[15] P. Pitchen, E. Dunach, M.N. Deshmukh, H.B. Kagan, J. Am. Chem. Soc.106 (1984) 8188-8193.

[16] F. Di Furia, G. Modena, R. Seraglia, Synthesis 4 (1984) 325-326.

[17] K. Kaczorowska, Z. Kolarska, K. Mitka, P. Kowalski, Tetrahedron 61 (2005) 83158327.

[18] J. Legros, J.R. Dehli, C. Bolm, Adv. Synth. Catal. 347 (2005) 19-31.

[19] I. Fernandez, N. Khiar, Chem. Rev. 103 (2003) 3651-3705.

[20] H.B. Kagan, Organosulfur Chemistry in Asymmetric Synthesis. T. Toru and C. Bolm Eds, WILEY-VCH Verlag GmbH \& Co. KGaA, Weinheim (2008) 1-29.

[21] M.C. Carreno, G. Hernandez-Torres, M. Rbagorda, A. Urbano, Chem. Commun. (2009) 6129-6144.

[22] G.E. O'Mahony, P. Kelly, S.E. Lawrence, A.R. Maguire, Arkivoc (i) (2011) 1-110.

[23] T. Katsuki, Pharmaceutical Process Chemistry, Edits, T. Shiori, I. Kunisuke, T. Konoike (2011) 59-76.

[24] J. Legros, C. Bolm, Angew. Chem., Int. Ed. Engl. 43 (2004) 4225-4228.

[25] J. Legros, C. Bolm, Chem. Eur. J. 11 (2005) 1086-1092.

[26] H. Egami, T. Katsuki, J. Am. Chem. Soc. 129 (2007) 8940-8941. 
[27] C. Duboc-Toia, S. Menage, C. Lambeaux, M. Fontecave, Tetrahedron Lett. 38 (1997) 3727-3730.

[28] C. Duboc-Toia, S. Menage, R.Y.N. Ho, L. Que Jr, C. Lambeaux, M. Fontecave, Inorg. Chem. 38 (1999) 1261-1268.

[29] Y. Mekmouche, , H. Hummel, R.Y.N. Ho, J. Que, L., V. Schünemannn, F. Thomas, A.X. Trautwein, C. Lebrun, K. Gorgy, J.C. Leprêtre, M.N. Collomb, A. Deronzier, M. Fontecave, S. Menage, Chem. Eur. J. 8 (2002) 1196-.

[30] J. Legros, C. Bolm, Angew. Chem., Int. Ed. Engl. 115 (2003) 5645-5647.

[31] A. Korte, J. Legros, C. Bolm, Synlett (2004) 2397-2399.

[32] H. Egami, T. Katsuki, Synlett 10 (2008) 1543-1546.

[33] K.A. Stingl, K.M. Weiß, S.B. Tsogoeva, Tetrahedron 68 (2012) 8493-8501.

[34] G. Simonneaux, P. Tagliatesta, J. Porph. and Phtalocyan. 8 (2004) 1166-1171.

[35] S. Oae, Y. Watanabe, K. Fujimori, Tetrahedron Lett. 23 (1982) 1189-1192.

[36] S. Colonna, N. Gaggero, G. Carrea, P. Pasta, J. Chem. Soc., Chem.Commun. (1992) 357-358.

[37] R.Z. Harris, S.L. Newmyer, P.R. Ortiz de Montellano, J. Biol. Chem. 268 (1993) 1637-1645.

[38] M.P.J. van Deurzen, F. van Rantwijk, R.A. Sheldon, Tetrahedron 53 (1997) 1318313220.

[39] E.N. Kadnikova, N.M. Kostic, J. Org. Chem. 68 (2003) 2600-2608.

[40] A. Suzumura, D. Paul, H. Sugimoto, S. Shinoda, R.R. Julian, J.L. Beauchamp, J. Teraoka, H. Tsukube, Inorg. Chem. 44 (2005) 904-910.

[41] F. van de Velde, I.W.C.E. Arends, R.A. Sheldon, J. Inorg. Biochem. 80 (2000) 81-89.

[42] J.T. Groves, P. Viski, J. Org. Chem. 55 (1990) 3628-3634.

[43. Y. Naruta, F. Tani, K. Maruyama, J. Chem. Soc, Chem. Commun. (1990) 1378-1380.

[44] Y. Naruta, F. Tani, K. Maruyama, Tetrahedron: Asymm. 2 (1991) 533-542.

[45] L.C. Chiang, K. Konishi, T. Aida, S. Inoue, J. Chem. Soc, Chem. Commun. (1992) 254-256.

[46] S. Inoue, T. Aida, K. Konoshi, J. Mol. Cat. A: Chem. 74 (1992) 121-129.

[47] Y. Ferrand, R. Daviaud, P. Le Maux, G. Simonneaux, Tetrahedron: Asymm. 17 (2006) 952-960.

[48] W. Nam, H.J. Han, S.-Y. Oh, Y.J. Lee, M.-H. Choi, S.-Y. Han, C. Kim, S.K. Woo, W. Shin, J. Am. Chem. Soc. 122 (2000) 8677-8684. 
[49] E. Baciocchi, M.F. Gerini, O. Lanzalunga, A. Lapi, M. Grazia Lo Piparo, Org. Biomol. Chem. 1 (2003) 422-426.

[50] M. Wolak, R. van Eldik, Chem. Eur. J. 13 (2007) 4873-4883.

[51] P. Le Maux, G. Simonneaux, Chem. Commun. 47 (2011) 6957-6959.

[52] G. Lente, I. Fabian, Dalton Trans. (2007) 4268-4275.

[53] O. Hamelin, S. Menage, F. Charnay, M. Chavarot, J.-L. Pierre, J. Pecaut, M. Fontecave, Inorg. Chem. 47 (2008) 6413-6420.

[54] I.W.C.E. Arends, T. Kodama, R.A. Sheldon, Oxidation using ruthenium catalysts in: Topics in Organometallic Chemistry 11, Ruthenium Catalysts and Fine Chemistry, Eds. C. Bruneau and P.H. Dixneuf, Springer-Verlag Berlin/Heidelberg, 2004, pp. 277320. 11 (2004) pp. 277-320.

[55] M. Chavarot, S. Menage, O. Hamelin, F. Charnay, J. Pecaut, M. Fontecave, Inorg. Chem. 42 (2003) 4810-4816.

[56] M. Palucki, P. Hanson, E.N. Jacobsen, Tetrahedron Lett. 33 (1992) 7111-7114.

[57] S. Schoumacker, O. Hamelin, J. Pecaut, M. Fontecave, Inorg. Chem. 42 (2003) 81108116.

[58] J. Brinksma, R. La Crois, B.L. Feringa, M.I. Donnoli, C. Rosini, Tetrahedron Lett. 42 (2001) 4049-4052.

[59] Z. Zhang, F. Guan, X. Huang, Y. Wang, Y. Sun, J. Mol. Cat. A: Chem. 364 (2012) 343-353.

[60] J.R. Carey, S.K. Ma, T.D. Pfister, D.K. Garner, H.K. Kim, J.A. Abramite, Z. Wang, Z. Guo, Y. Lu, J. Am. Chem. Soc. 126 (2004) 10812-10813.

[61] J.-L. Zhang, D.K. Garner, L. Liang, Q. Chen, Y. Lu, Chem. Commun. (2008) 16651667.

[62] J.-L. Zhang, D.K. Garner, L. Liang, D.A. Barrios, Y. Lu, Chem. -Eur. J. 15 (2009) 7481-7489.

[63] A. Marques, M. Marin, M.F. Ruasse, J. Org. Chem. 66 (2001) 7588-7595.

[64] H. Srour, J. Jalkh, P. Le Maux, S. Chevance, M. Kobeissi, G. Simonneaux, J. Mol. Cat. A: Chem. 370 (2013) 75-79.

[65] I. Nigel-Etinger, A. Mahammed, Z. Gross, Catal. Sci. Technol. 1 (2011) 578-581.

[66] A. Mahammed, Z. Gross, J. Am. Chem. Soc. 127 (2005) 2883-2887.

[67] K. Yoshinaga, N. Itoh, T. Kito, Polymer J. 23 (1991) 65-68.

[68] C. Bolm, Coord. Chem. Rev. 237 (2003) 245-256.

[69] K.P. Volcho, N.F. Salakhutdinov, Russ. Chem. Rev. 78 (2009) 457-464. 
[70] C. Bolm, F. Bienewald, Angew. Chem., Int. Ed. Engl. 34 (1995) 2640-2642.

[71] A.H. Vetter, A. Berkessel, Tetrahedron Lett. 39 (1998) 1741-1744.

[72] C. Ohta, H. Shimizu, A. Kondo, T. Katsuki, Synlett 1 (2002) 161-163.

[73] B. Pelotier, M.S. Anson, I.B. Campbell, S.J.F. Macdonald, G. Priem, R.F.W. K. Jackson, Synlett 7 (2002) 1055-1060.

[74] Y.-C. Jeong, S. Choi, Y.D. Hwang, K.-H. Ahn, Tetrahedron Lett. 45 (2004) 92499252.

[75] P. Plitt, H. Pritzkow, T. Oeser, R. Kraemer, J. Inorg. Biochem. 99 (2005) 1230-1237.

[76] A. Gao, M. Wang, D. Wang, L. Zhang, H. Liu, W. Tian, L. Sun, Chin. J. Cat. 27 (2006) 743-748.

[77] H. Liu, M. Wang, Y. Wang, R. Yin, W. Tian, L. Sun, Appl. Organomet. Chem. 22 (2008) 253-257.

[78] Y. Wang, M. Wang, Y. Wang, X. Wang, L. Wang, L. Sun, J. Cat. 273 (2010) 177-181.

[79] E.V. Ashikhmina, S.A. Rubtsova, I.A. Dvornikova, A.V. Kuchin, Russ. J. Org. Chem. 45 (2009) 1509-1514.

[80] N.N. Karpyshev, O.D. Yakovleva, E.P. Talsi, K.P. Bryliakov, O.V. Tolstikova, A.G. Tolstikov, J. Mol. Cat. A: Chem. 157 (2000) 91-95.

[81] J. Sun, C. Zhu, Z. Dai, M. Yang, Y. Pan, H. Hu, J. Org. Chem. 69 (2004) 8500-8503.

[82] Q. Zeng, H. Wang, T. Wang, Y. Cai, W. Weng, Y. Zhao, Adv. Synth. Catal. 347 (2005) 1933-1936.

[83] C. Drago, L. Caggiano, R.F.W. Jackson, Angew. Chem., Int. Ed. Engl. 44 (2005) 7221-7223.

[84] G. Liu, D.A. Cogan, J.A. Ellman, J. Am. Chem. Soc. 119 (1997) 9913-9914.

[85] D.A. Cogan, G. Liu, K. Kim, B.J. Backes, J.A. Ellman, J. Am. Chem. Soc. 120 (1998) 8011-8019.

[86] J. Skarzewski, E.b. Ostrycharz, R. Siedlecka, Tetrahedron: Asymm. 10 (1999) 34573461 .

[87] S.A. Blum, R.G. Bergman, J.A. Ellman, J. Org. Chem. 68 (2002) 150-155.

[88] J. Hartung, S. Drees, M. Greb, P. Schmidt, I. Svoboda, H. Fuess, A. Murso, D. Stalke, Eur. J. Org. Chem. 2003 (2003) 2388-2408.

[89] S.-H. Hsieh, Y.-P. Kuo, H.-M. Gau, Dalton Trans. (2007) 97-106.

[90] G. Romanowski, T. Lis, Inorg. Chim. Acta 394 (2013) 627-634.

[91] T. Miyazaki, T. Katsuki, Synlett 7 (2003) 1046-1048.

[92] B. Saito, T. Katsuki, Tetrahedron Lett. 42 (2001) 3873-3876. 
[93] B. Saito, T. Katsuki, Tetrahedron Lett. 42 (2001) 8333-8336.

[94] T. Tanaka, B. Saito, T. Katsuki, Tetrahedron Lett. 43 (2002) 3259-3262.

[95] B. Saito, T. Katsuki, Chirality 15 (2003) 24-27.

[96] K.P. Bryliakov, E.P. Talsi, J. Mol. Cat. A: Chem. 264 (2007) 280-287.

[97] K.P. Bryliakov, E.P. Talsi, Eur. J. Org. Chem. (2008) 3369-3376.

[98] H. Blumenthal, J. Liebscher, Arkivoc (xi) (2009) 204-220.

[99. K.P. Bryliakov, E.P. Talsi, Eur. J. Org. Chem. 2011 (2011) 4693-4698.

[100] E.P. Talsi, K.P. Bryliakov, Appl. Organomet. Chem. 27 (2013) 239-244.

[101] S. Barman, S. Patil, C.J. Levy, Chem. Lett. 41 (2012) 974-975.

[102] P. Adão, F. Avecilla, M. Bonchio, M. Carraro, J. Costa Pessoa, I. Correia, Eur. J. Inorg. Chem. 2010 (2010) 5568-5578.

[103] P.K. Bera, D. Ghosh, S.H.R. Abdi, N.H. Khan, R.I. Kureshy, H.C. Bajaj, J. Mol. Cat. A: Chem. 361-362 (2012) 36-44.

[104] A. Scarso, G. Strukul, Adv. Synth. Catal. 347 (2005) 1227-1234.

[105] H.-B. Zhu, Z.-Y. Dai, W. Huang, K. Cui, S.-H. Gou, C.-J. Zhu, Polyhedron 23 (2004) 1131-1137.

[106] P. Kelly, S.E. Lawrence, A.R. Maguire, Synlett (2007) 1501-1506.

[107] G.E. O'Mahony, A. Ford, A.R. Maguire, J. Org. Chem. 77 (2012) 3288-3296.

[108] T. Yamaguchi, K. Matsumoto, B. Saito, T. Katsuki, Angew. Chem., Int. Ed. Engl. 46 (2007) 4729-4731.

[109] K. Matsumoto, T. Yamaguchi, J. Fujisaki, B. Saito, T. Katsuki, Chem. Asian J. 3 (2008) 351-358.

[110] K. Matsumoto, T. Yamaguchi, T. Katsuki, Chem. Commun. (2008) 1704-1706.

[111] J. Fujisaki, K. Matsumoto, K. Matsumoto, T. Katsuki, J. Am. Chem. Soc. 133 (2011) 56-61.

[112] V.V. Thakur, A. Sudalai, Tetrahedron: Asymm. 14 (2003) 407-410.

[113] Y. Zhang, J.T. Sun, C.J. Zhu, Chin. Chem. Lett. 17 (2006) 1173-1176.

[114] M. Carraro, G. Modugno, A. Sartorel, G. Scorrano, M. Bonchio, Eur. J. Inorg. Chem. 2009 (2009) 5164-5174.

[115] Q.H. Xia, H.Q. Ge, C.P. Ye, Z.M. Liu, K.X. Su, Chem. Rev. 105 (2005) 1603-1662.

[116] G. De Faveri, G. Ilyashenko, M. Watkinson, Chem. Soc. Rev. 40 (2011) 1722-1760.

[117] M.B. Francis, E.N. Jacobsen, Angew. Chem., Int. Ed. Engl. 38 (1999) 937-941.

[118] T. Katsuki, K.B. Sharpless, J. Am. Chem. Soc.102 (1980) 5974-5976. 
[119] C. Bolm, O. Beckmann, T. Kühn, C. Palazzi, W. Adam, P.B. Rao, C.R. Saha-Möller, Tetrahedron: Asymm. 12 (2001) 2441-2446.

[120] D. Meunier, A. Piechaczyk, A. de Mallmann, J.-M. Basset, Angew. Chem., Int. Ed. Engl. 38 (1999) 3540-3542.

[121] W. Zhang, A. Basak, Y. Kosugi, Y. Hoshino, H. Yamamoto, Angew. Chem., Int. Ed. Engl. 44 (2005) 4389-4391.

[122] Z. Bourhani, A.V. Malkov, Chem. Commun. (2005) 4592-4594.

[123] H. Egami, T. Katsuki, Angew. Chem., Int. Ed. Engl. 47 (2008) 5171-5174.

[124] H. Egami, T. Oguma, T. Katsuki, J. Am. Chem. Soc. 132 (2010) 5886-5895.

|[125] E.P. Talsi, K.P. Bryliakov, Coord. Chem. Rev. 256 (2012) 1418-1434.

[126] D. Mansuy, Comp. Biochem. Physiol. 121C (1998) 5-14.

[127] B. Meunier, S.P. de Visser, S. Shaik, Chem. Rev. 104 (2004) 3947-3980.

[128] E. Rose, B. Andrioletti, S. Zrig, M. Quelquejeu-Etheve, Chem. Soc. Rev. 34 (2005) 573-583.

[129] M.C. White, A.G. Doyle, E.N. Jacobsen, J. Am. Chem. Soc. 123 (2001) 7194-7195.

[130] F.G. Gelalcha, B. Bitterlich, G. Anilkumar, M.K. Tse, M. Beller, Angew. Chem., Int. Ed. Engl. 46 (2007) 7293-7296.

[131] F.G. Gelalcha, G. Anilkumar, M.K. Tse, A. Brückner, M. Beller, Chem. Eur. J. 14 (2008) 7687-7698.

[132] O.Y. Lyakin, R.V. Ottenbacher, K.P. Bryliakov, E.P. Talsi, ACS Catal. 2 (2012) 1196-1202.

[133] M. Wu, C.-X. Miao, S. Wang, X. Hu, C. Xia, F.E. Kühn, W. Sun, Adv. Synth. Catal. 353 (2011) 3014-3022.

[134] P.R.E. Ortiz de Montellano, in Cytochrome P-450: Structure, Mechanism and Biochemistry (2nd edn) Plenum Press, New York, 1995 (1995).

[135] H. Joo, Z. Lin, F.H. Arnold, Nature 399 (1999) 670-673.

[136] P.C. Cirino, F.H. Arnold, Adv. Synth. Catal. 344 (2002) 932-937.

[137] T. Fujishiro, O. Shoji, S. Nagano, H. Sugimoto, Y. Shiro, Y. Watanabe, J. Biol. Chem. 286 (2011) 29941-29950.

[138] O. Shoji, Y. Watanabe, Metallomics 3 (2011) 379-388.

[139] C.M. Che, J.S. Huang, Chem. Commun. (2009) 3996-4015.

[140] J.T. Groves, T.E. Nemo, R.S. Myers, J. Am. Chem. Soc. 101 (1979) 1032-1033.

[141] J.T. Groves, R.S. Myers, J. Am. Chem. Soc. 105 (1983) 5791-5796. 
[142] B. Boitrel, A. Lecas, Z. Renko, E. Rose, J. Chem. Soc., Chem. Commun. (1985) 18201821.

[143] D. Mansuy, P. Battioni, J.P. Renaud, P. Guerin, J. Chem. Soc., Chem. Commun. (1985) 155-156.

[144] B. Boitrel, A. Lecas, Z. Renko, E. Rose, New J. Chem. 13 (1989) 73-99.

[145] J.P. Collman, X. Zhang, V.J. Lee, E.S. Uffelman, J.I. Brauman, Science 261 (1993) 1404-1411.

[146] Z. Gross, S. Ini, J. Org. Chem. 62 (1997) 5514-5521.

[147] Y. Naruta, F. Tani, N. Ishihara, K. Maruyama, J. Am. Chem. Soc 113 (1991) 68656872.

[148] S.J. Yang, W. Nam, Inorg. Chem. 37 (1998) 606-607.

[149] N.A. Stephenson, A.T. Bell, J. Am. Chem. Soc. 127 (2005) 8635-8643.

[150] P. Le Maux, H. Srour, G. Simonneaux, Tetrahedron 68 (2012) 5824-5828.

[151] R.M. Stoop, A. Mezzetti, Green Chem. 1 (1999) 39-41.

[152] R.M. Stoop, S. Bachmann, M. Valentini, A. Mezzetti, Organometallics 19 (2000) 4117-4126.

[153] M.K. Tse, C. Dobler, S. Bhor, M. Klawonn, W. Magerlein, H. Hugl, M. Beller, Angew. Chem., Int. Ed. Engl. 43 (2004) 5255-5260.

[154] H. Nishiyama, T. Shimada, K. Aoki, H. Itoh, H. Sugiyama, Y. Motoyama, Chem. Commun. (1997) 1863-1864.

[155] M.K. Tse, M. Klawonn, S. Bhor, C. Dobler, G. Anilkumar, H. Hugl, W. Magerlein, M. Beller, Org. Lett. (2005) 987-990.

[156] S. Bhor, G. Anilkumar, M.K. Tse, M. Klawonn, C. Dobler, B. Bitterlich, A. Grotevendt, M. Beller, Org. Lett. 7 (2005) 3393-3396.

[157] W. Zhang, J.L. Loebach, S.R. Wilson, E.N. Jacobsen, J. Am. Chem. Soc. 112 (1990) 2801-2803.

[158] E.N. Jacobsen, W. Zhang, A.R. Muci, J.R. Ecker, L. Deng, J. Am. Chem. Soc. 113 (1991) 7063-7064.

[159] M. Palucki, P.J. Pospisil, W. Zhang, E.N. Jacobsen, J. Am. Chem. Soc. 116 (1994) 9333-9334.

[160] R. Irie, K. Noda, Y. Ito, N. Matsumoto, T. Katsuki, Tetrahedron Lett. 31 (1990) 73457348.

[161] R. Irie, K. Noda, Y. Ito, N. Matsumoto, T. Katsuki, Tetrahedron: Asymm. 2 (1991) 481-494. 
[162] R. Irie, N. Hosoya, T. Katsuki, Synlett (1994) 255-256.

[163] P. Pietikainen, Tetrahedron Lett. 35 (1994) 941-944.

[164] T. Schwenkreis, A. Berkessel, Tetrahedron Lett. 34 (1993) 4785-4788.

[165] A. Berkessel, M. Frauenkron, T. Schwenkreis, A. Steinmetz, G. Baum, D. Fenske, J. Mol. Cat. A: Chem. 113 (1996) 321-342.

[166] C. Bolm, D. Kadereit, M. Valacchi, Synlett (1997) 687-688.

[167] V.B. Romakh, B. Therrien, G. Suss-Fink, G.B. Shulpin, Inorg. Chem. 46 (2007) 13151331.

[168] M. Wu, B. Wang, S. Wang, C. Xia, W. Sun, Org. Lett. 11 (2009) 3622-3625.

[169] J. Teixeira, A.R. Silva, L.C. Branco, C.A.M. Afonso, C. Freire, Inorg. Chim. Acta 363 (2010) 3321-3329.

[170] R.V. Ottenbacher, K.P. Bryliakov, E.P. Talsi, Adv. Synth. Catal. 353 (2011) 885-889.

[171] N.C. Maity, G.V.S. Rao, K.J. Prathap, S.H.R. Abdi, R.I. Kureshy, N.-u.H. Khan, H.C. Bajaj, J. Mol. Cat. A: Chem. 366 (2013) 380-389.

[172] S. Vilain, P. Maillard, M. Momenteau, J. Chem. Soc., Chem. Commun. (1994) 16971698.

[173] S. Vilain-Deshayes, A. Robert, P. Maillard, B. Meunier, M. Momenteau, J. Mol. Cat. A: Chem. 113 (1996) 23-34.

[174] J.P. Collman, V.J. Lee, C.J. Kellen-Yuen, X. Zang, J.A. Ibers, J.I. Brauman, J. Am. Chem. Soc. 117 (1995) 692-703.

[175] H. Srour, P. Le Maux, G. Simonneaux, Inorg. Chem. 51 (2012) 5850-5856.

[176] G. Chatel, C. Goux-Henry, A.s. Mirabaud, T. Rossi, N. Kardos, B. Andrioletti, M. Draye, J. Catal. 291 (2012) 127-132.

[177] Y. Chu, X. Liu, W. Li, X. Hu, L. Lin, X. Feng, Chem. Sci. 3 (2012) 1996-2000.

[178] K. Matsumoto, Y. Sawada, B. Saito, K. Sakai, T. Katsuki, Angew. Chem., Int. Ed. Engl. 44 (2005) 4935-4939.

[179] Y. Sawada, K. Matsumoto, T. Katsuki, Angew. Chem., Int. Ed. Engl. 46 (2007) 45594561 .

[180] Y. Sawada, K. Matsumoto, S. Kondo, H. Watanabe, T. Ozawa, K. Suzuki, B. Saito, T. Katsuki, Angew. Chem., Int. Ed. Engl. 45 (2006) 3478-3480.

[181] K. Matsumoto, Y. Sawada, T. Katsuki, Pure Appl. Chem. Commun. 80 (2008) 10711077.

[182] K. Matsumoto, C. Feng, S. Handa, T. Oguma, T. Katsuki, Tetrahedron 67 (2011) 6474-6478. 
[183] R. Sinigalia, R.A. Michelin, F. Pinna, G. Strukul, Organometallics 6 (1987) 728-734.

[184] M. Colladon, A. Scarso, G. Strukula, Adv. Synth. Catal. (2007) 797-801.

[185] A.E. Prasetyanto, N.H. Khan, H.U. Seo, S.E. Park, Top. Catal. 53 (2010) 1381-1386.

[186] W.A. Herrmann, F.E. Kahn, Acc. Chem. Res. 30 (1997) 169-180.

[187] C.C. Romao, F.E. Kahn, W.A. Herrmann, Chem. Rev. 97 (1997) 3197-3246.

[188] F.E. Kahn, J. Zhao, W.A. Herrmann, Tetrahedron: Asymm. 16 (2005) 3469-3479.

[189] M.Ì.J. Sabater, M.E. Domine, A. Corma, J. Catal. 210 (2002) 192-197.

[190] J.J. Haider, R.M. Kratzer, W.A. Herrmann, J. Zhao, F.E. Kahn, J. Organomet. Chem. 689 (2004) 3735-3740.

[191] S. Li, B. Zhang, F.E. Kahn, J. Organomet. Chem. (2013) in press.

[192] Z.-M. Wang, K. Kakiuchi, K.B. Sharpless, J. Org. Chem. 59 (1994) 6895-6897.

[193] H.C. Kolb, M.S. VanNieuwenhze, K.B. Sharpless, Chem. Rev. 94 (1994) 2483-2547.

[194] B. Balagam, R. Mitra, D.E. Richardson, Tetrahedron Lett. 49 (2008) 1071-1075.

[195] S.Y. Jonsson, K. Färnegardh, J.-E. Bäckvall, J. Am. Chem. Soc. 123 (2001) 13651371.

[196] M. Costas, A.K. Tipton, K. Chen, D.-H. Jo, L. Que, J. Am. Chem. Soc. 123 (2001) $6722-6723$.

[197] K. Suzuki, P.D. Oldenburg, J. Que, L., Angew. Chem., Int. Ed. Engl. 47 (2008) 18871889.

[198] J.W. de Boer, W.R. Browne, J. Brinksma, P.L. Alsters, R. Hage, B.L. Feringa, Inorg. Chem. 46 (2007) 6353-6372.

[199] J.W. de Boer, W.R. Browne, S.R. Harutyunyan, L. Bini, T.D. Tiemersma-Wegman, P.L. Alsters, R. Hage, B.L. Feringa, Chem. Commun. (2008) 3747-3749.

[200] P. Saisaha, J.W. de Boer, W.R. Browne, Chem. Soc. Rev. 42 2059-2074.

[201] B.M. Choudary, N.S. Chowdari, S. Madhi, M.L. Kantam, J. Org. Chem. 68 (2003) 1736-1746.

[202] H. Sugimoto, K. Kitayama, S. Mori, S. Itoh, J. Am. Chem. Soc. 134 (2012) 1927019280.

[203] A.S. Borovik, Chem. Soc. Rev. 40 (2011) 1870-1874.

[204] C.M., Che, V.K.Y. Lo, C.Y. Zhou, J.S. Huang, Chem. Soc. Rev. 40 (2011) 19501975.

[205] H. Lu, X.P. Zhang, Chem. Soc. Rev. 40 (2011) 1899-1909.

[206] P.R. Ortiz de Montellano, Chem. Rev. 110 (2009) 932-948. 
[207] M. Kinne, M.R. Poraj-Kobielska, S. A., R. Ullrich, M. Hofrichter, K.E. Hammel, J. Biol. Chem. 284 (2009) 29343.

[208] X. Wang, S. Peter, M. Kinne, M. Hofrichter, J.T. Groves, J. Am. Chem. Soc. 134 12897-12900.

[209] Y. Mekmouche, C. Duboc-Toia, S. Menage, C. Lambeaux, M. Fontecave, J. Mol. Catal. A: Chem. 156 (2000) 85-89.

[210] J.T. Groves, P. Viski, J. Am. Chem. Soc. 111 (1989) 8537-8538.

[211] Z. Gross, S. Ini, Org. Lett. 1 (1999) 2077-2080.

[212] R. Zhang, W.-Y. Yu, T.-S. Lai, C.-M. Che, Chem. Commun. (1999) 1791-1792.

[213] R. Zhang, W.-Y. Yu, C.-M. Che, Tetrahedron: Asymm. 16 (2005) 3520-3526.

[214] G. Simonneaux, P. Le Maux, Y. Ferrand, J. Rault-Berthelot, Coord. Chem. Rev. 250 (2006) 2212-2221. 
Table 1. Selected catalytic asymmetric sulfoxidation of thioanisole with $\mathrm{H}_{2} \mathrm{O}_{2}$

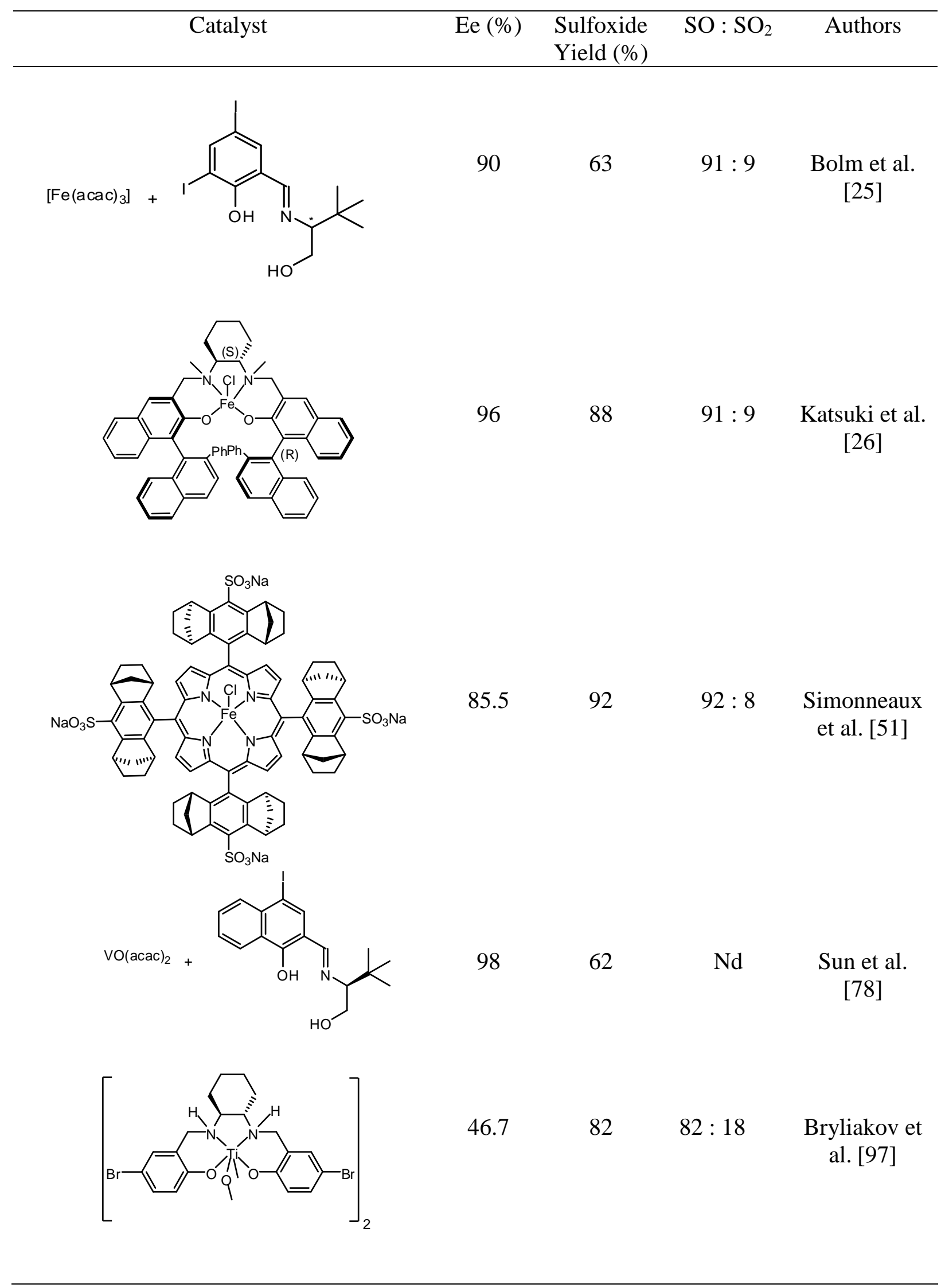




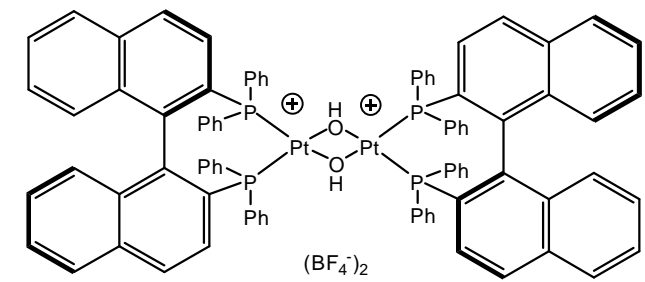

99: $1 \quad$ Strukul et al. [104]

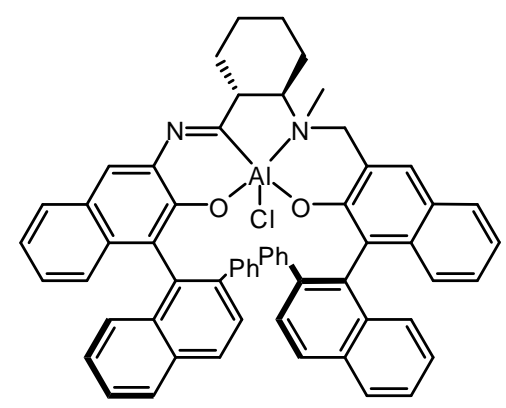

99

78

$86: 14 \quad$ Katsuki et al.

[108] 
Table 2: Selected asymmetric epoxidation catalyzed by metal complexes with $\mathrm{H}_{2} \mathrm{O}_{2}$

Substrate
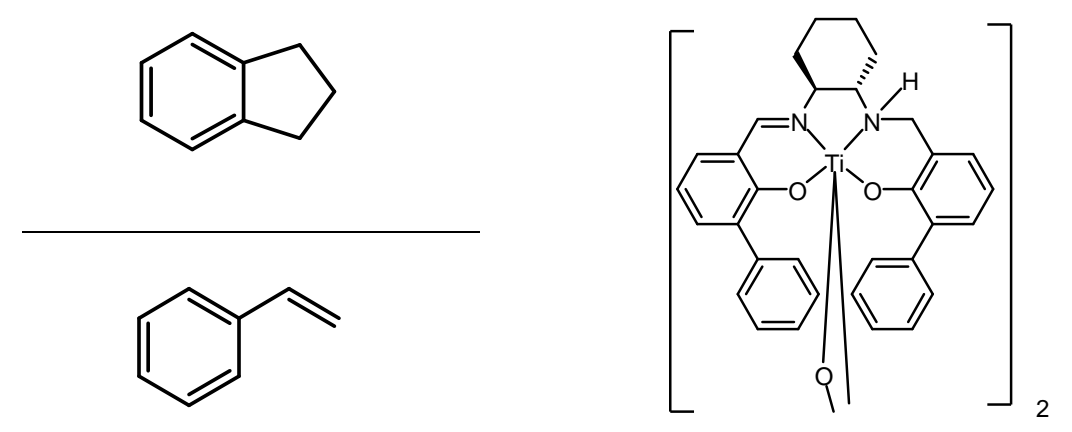

99

Katsuki el al.

[181]

92
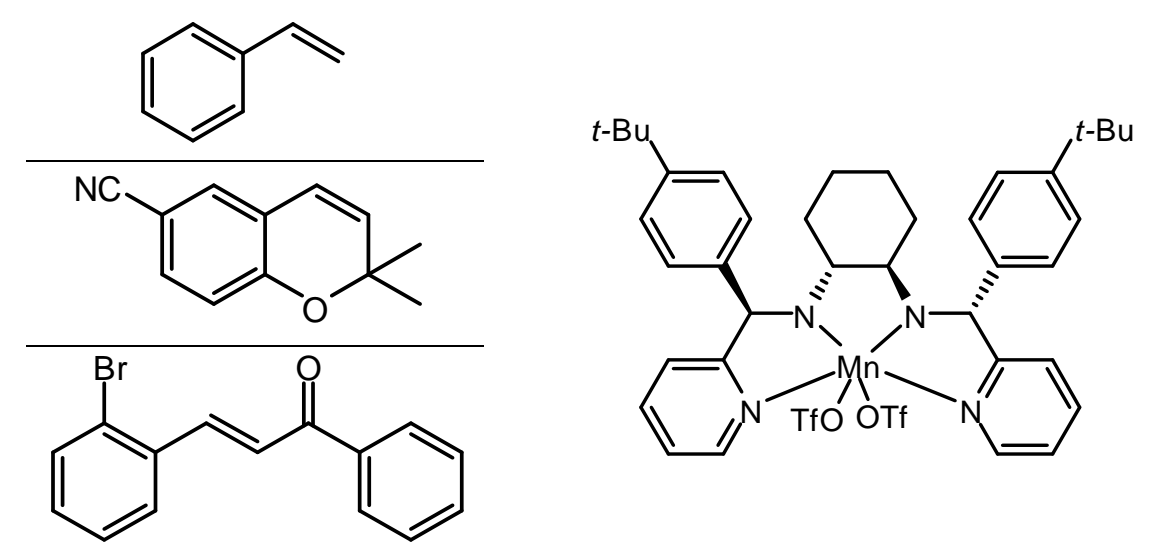

44

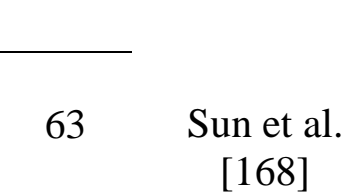




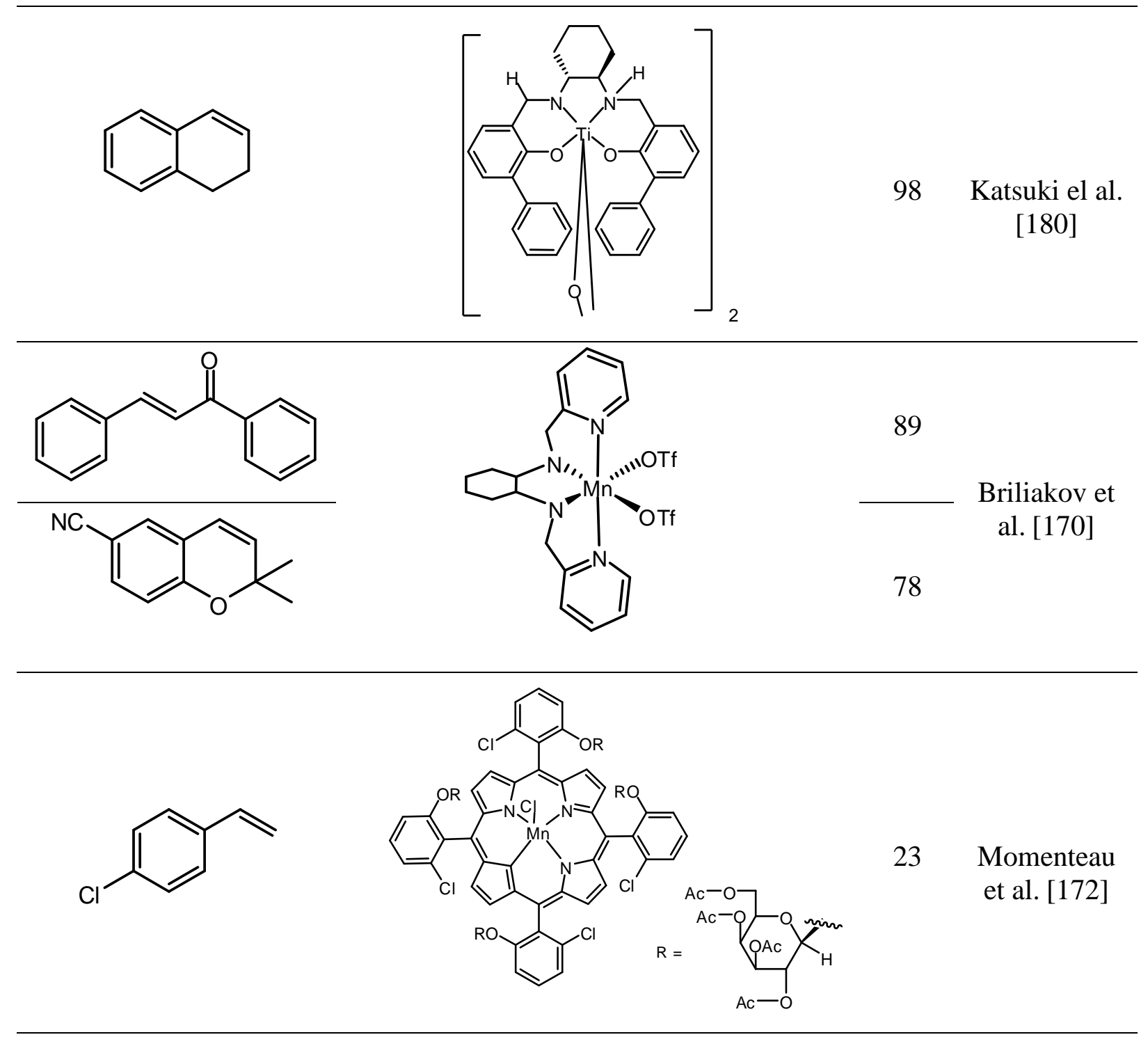

$\longrightarrow$

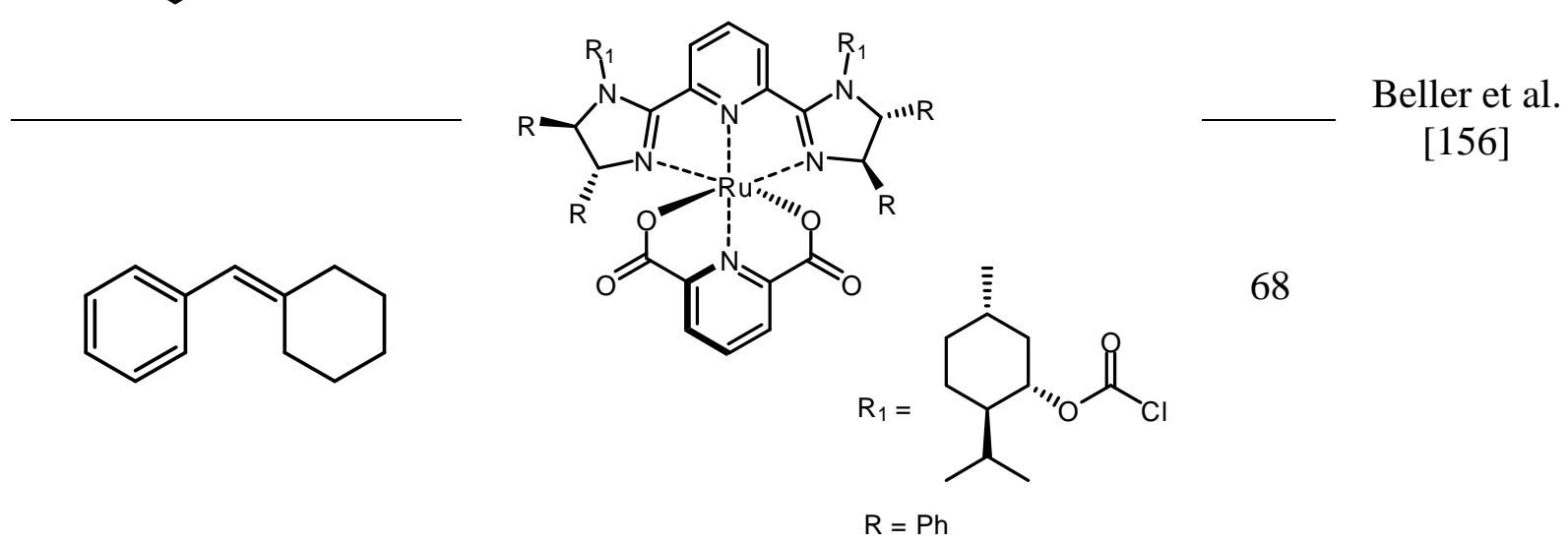




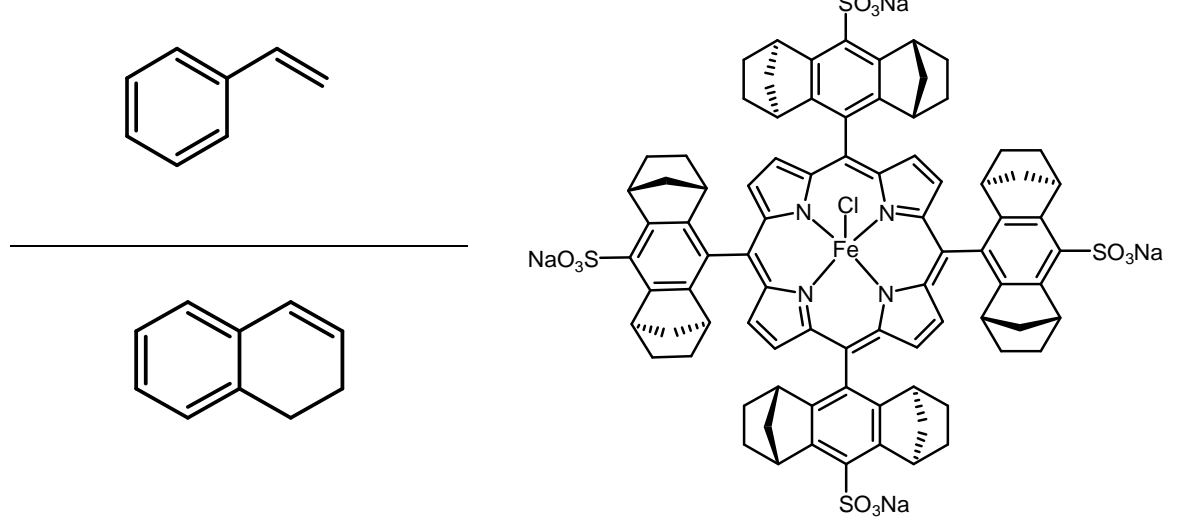<smiles>C1=Cc2ccccc2CC1</smiles>

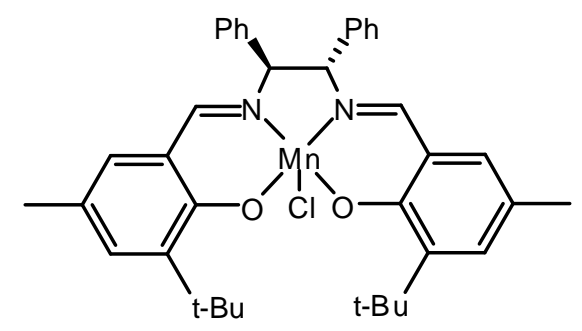<smiles>C1=Cc2ccccc2CC1</smiles>

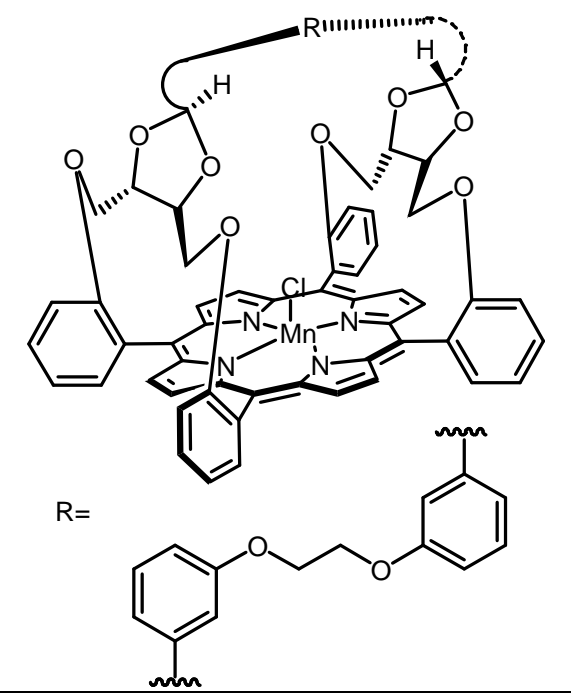




\section{FIGURES}

Figure 1. Structures of Sulindac and Modafinil.

Figure 2. Selected ligands for asymmetric sulfoxidation from primary amine-derived nonsymmetrical Schiff bases [33].

Figure 3. Halterman iron tetrasulfonated porphyrin [51] and Halterman manganese tetrasulfonated porphyrin [175].

Figure 4. Structures of the two enantiomers of ruthenium complexes [55].

Figure 5. Structures of salen manganese complexes [56].

Figure 6. Schiff base ligands used by Bolm with $\mathrm{VO}(\mathrm{acac})_{2}$ (acac: acetylacetonate) [70].

Figure 7. Structure of $\{[(\mathrm{R})-\mathrm{BINAP}] \mathrm{Pt}(\mathrm{m}-\mathrm{OH})\}_{2}(\mathrm{BF} 4)_{2}$ complex for catalyzed asymmetric sulfoxidation of prochiral aryl alkyl sulfides with hydrogen peroxide in water with surfactants [104].

Figure 8. Aluminium(salalen) complex as catalyst for asymmetric sulfoxidation in the presence of hydrogen peroxide [111].

Figure 9. Chiral iron complexes for enantioselective epoxidation of $\alpha, \beta$-unsaturated ketones [133].

Figure 10. Chiral pentadentate dihydrosalen manganese complex for epoxidation of olefins [164].

Figure 11. Chiral non-heme aminopyridine manganese complexes [170].

Figure 12. Chiral manganese porphyrins bearing glycosyl groups [172].

Figure 13. Niobium(salan) complexes [123].

Figure 14. Optically active ligands used after iron complexation for asymmetric cisdihydroxylation [197]. 


\section{SCHEMES}

Scheme 1. Oxidation of sulfide catalyzed by iron mononuclear A or dinuclear B complexes [29].

Scheme 2. Non-heme iron-catalyzed enantioselective sulfoxidation [24].

Scheme 3. Asymmetric oxidation of sulfides with Fe(salan) [32].

Scheme 4. Synthesis of ligands from a chiral cyclohexyl diamine backbone [57].

Scheme 5. Sulfoxidation of tert-butyl disulfide catalyzed by vanadium complexes [85].

Scheme 6. Asymmetric oxidation by Ti(salen) complex [94].

Scheme 7. Asymmetric epoxidation catalyzed by iron and chiral ligands bearing sulfonyl group [130].

Scheme 8. Chiral bipyrrolidine ligand based iron and manganes complexes [132] .

Scheme 9. Asymmetric epoxidation catalyzed by chiral tetradentate Ru(II) complexes [152]

Scheme 10 Ruthenium-pybox- catalyzedasymmetric epoxidation of styrene [153]

Scheme 11. Synthesis of a Pybim library [156].

Scheme 12. Enantioselective epoxidation of chromene catalyzed by Mn(salen) complex [162]

Scheme 13. Asymmetric epoxidation of olefins catalyzed by chiral tetradentate N4

Manganese complexes [168].

Scheme 14. Ti(salalen)-catalyzed asymmetric epoxidation [181].

Scheme 15. Asymmetric epoxidation of 1,2-dihydronaphtalene with Ti(salan) complex [181].

Scheme 16. Asymmetric epoxidation of terminal alkenes with hydrogen peroxide catalyzed by chiral Pt complexes [184].

Scheme 17. Asymmetric cis-dihydroxylation of chromene with $\mathrm{H}_{2} \mathrm{O}_{2}$ catalyzed by manganese complex [199].

Scheme 18. Enantioselective hydroxylation of alkane with $\mathrm{H}_{2} \mathrm{O} 2$ by non-heme iron complex [209]. 
<smiles>CC1=C(CC(=O)O)c2cc(F)ccc2/C1=C\c1ccc([S+](C)=O)cc1</smiles>

(A)<smiles>NC(=O)CS(=O)C(c1ccccc1)c1ccccc1</smiles>

(B)

Figure 1. Structures of Sulindac (A) and Modafinil (B).
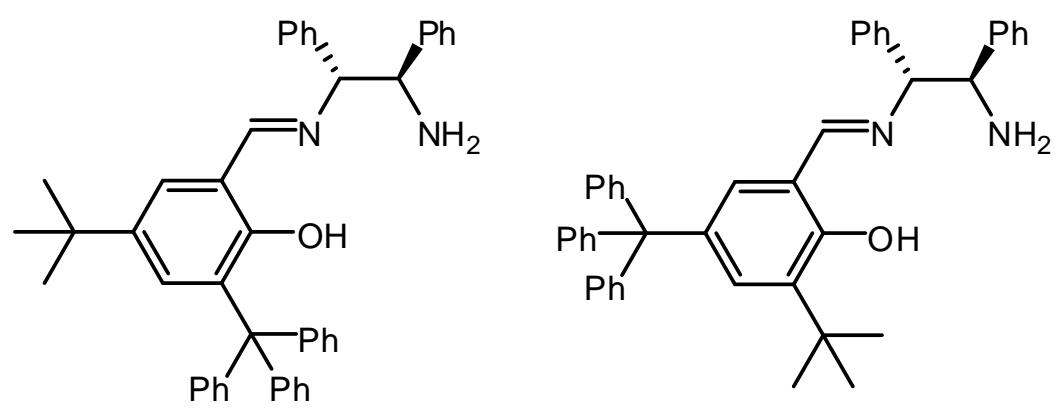

Figure 2. Selected ligands for asymmetric sulfoxidation from primary amine-derived nonsymmetrical Schiff bases [33]. 


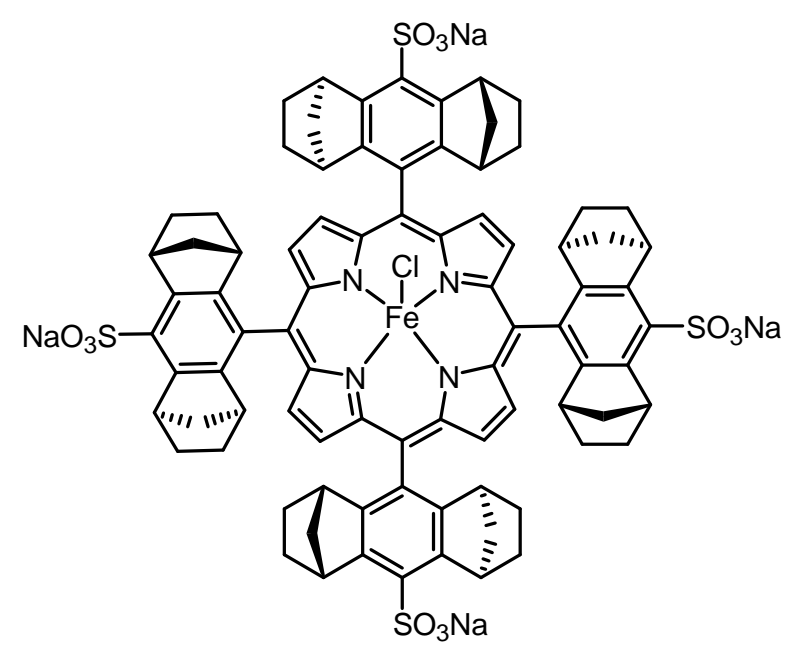

1 FeClHaltS

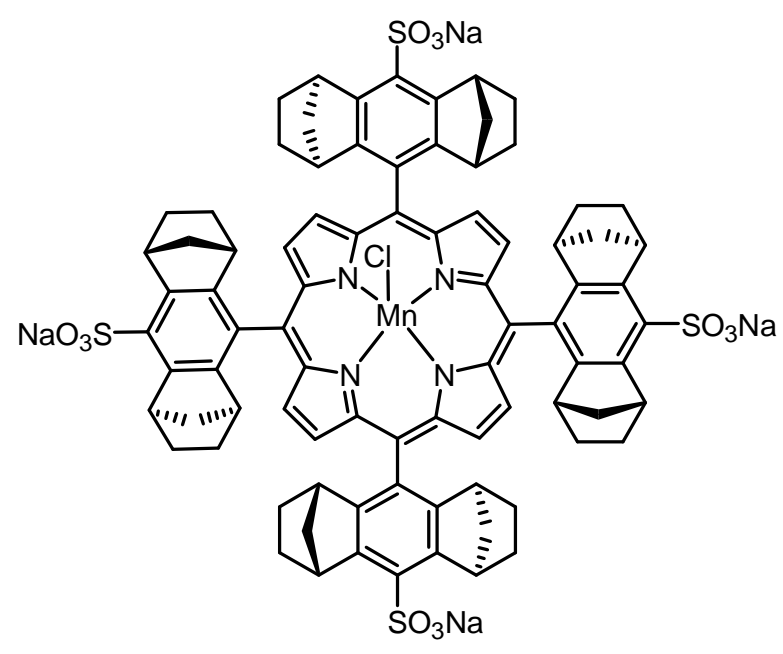

$2 \mathrm{MnClHaltS}$

Figure 3. Halterman iron tetrasulfonated porphyrin [51] and Halterman manganese tetrasulfonated porphyrin [175].
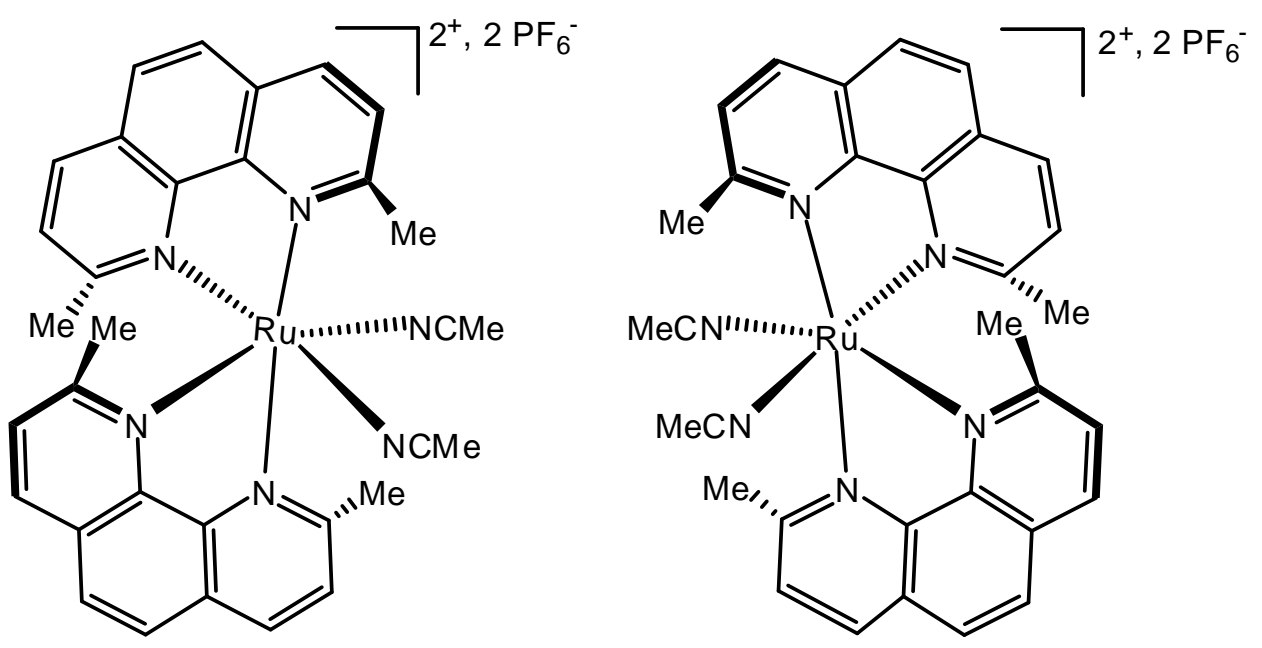

Figure 4. Structures of the two enantiomers of ruthenium complexes [55]. 

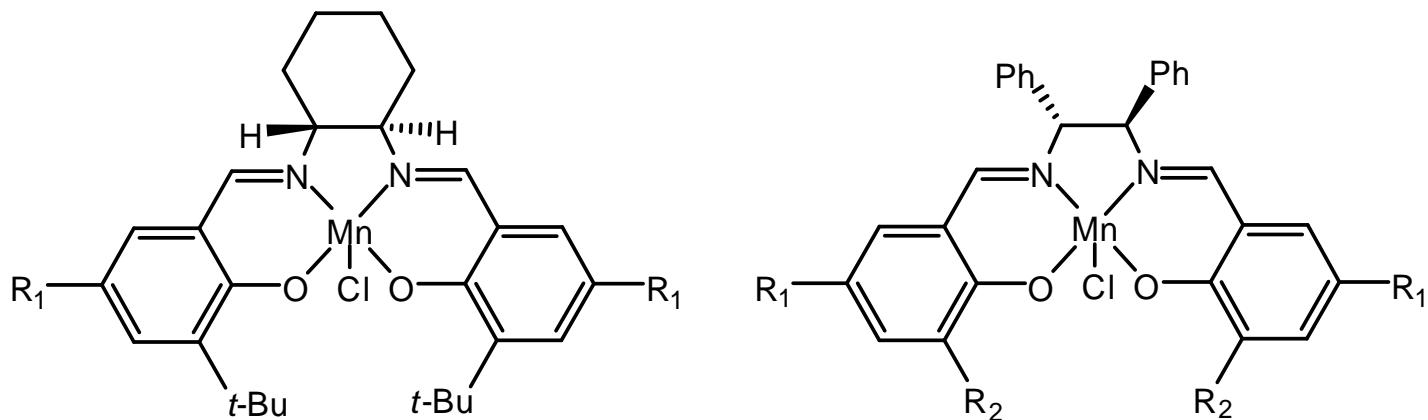

$$
\begin{aligned}
& \mathrm{R}_{1}=\mathrm{OMe} \\
& \mathrm{R}_{1}=t-\mathrm{Bu} \\
& \mathrm{R}_{1}=\mathrm{NO}_{2} \\
& \mathrm{R}_{1}=\mathrm{H}
\end{aligned}
$$

$$
\begin{aligned}
& \mathrm{R}_{1}=\mathrm{OMe}, \mathrm{R}_{2}=t-\mathrm{Bu} \\
& \mathrm{R}_{1}=t-\mathrm{Bu}, \mathrm{R}_{2}=t-\mathrm{Bu} \\
& \mathrm{R}_{1}=\mathrm{Me}, \mathrm{R}_{2}=t-\mathrm{Bu} \\
& \mathrm{R}_{1}=\mathrm{OMe}, \mathrm{R}_{2}=\mathrm{H}
\end{aligned}
$$

Figure 5. Structure of salen manganese complexes [56].<smiles>[X]c1cc([R])c(O)c(/C=N/C(CO)C(C)(C)C)c1</smiles>
$\mathrm{a}: \mathrm{R}=t-\mathrm{Bu}, \mathrm{X}=\mathrm{NO}_{2}$
$\mathrm{b}: \mathrm{R}=\mathrm{X}=t-\mathrm{Bu}$
c: $\mathrm{R}=\mathrm{SiPh}_{2} t-\mathrm{Bu}, \mathrm{X}=t-\mathrm{Bu}$
$\mathrm{d}: \mathrm{R}=\mathrm{H}, \mathrm{X}=\mathrm{NO}_{2}$

Figure 6. Schiff base ligands used by Bolm and co-workers with $\mathrm{VO}(\mathrm{acac})_{2}$ (acac: acetylacetonate) [70]. 


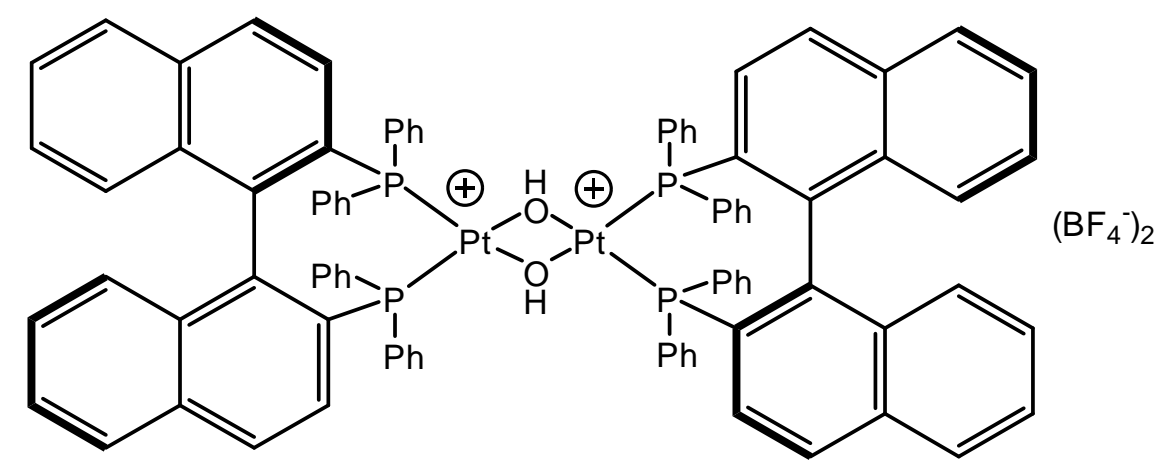

Figure 7. Structure of $\{[(\mathrm{R})-\mathrm{BINAP}] \mathrm{Pt}(\mathrm{m}-\mathrm{OH})\}_{2}(\mathrm{BF} 4)_{2}$ complex for catalyzed asymmetric sulfoxidation of prochiral aryl alkyl sulfides with hydrogen peroxide in water with surfactants [104].

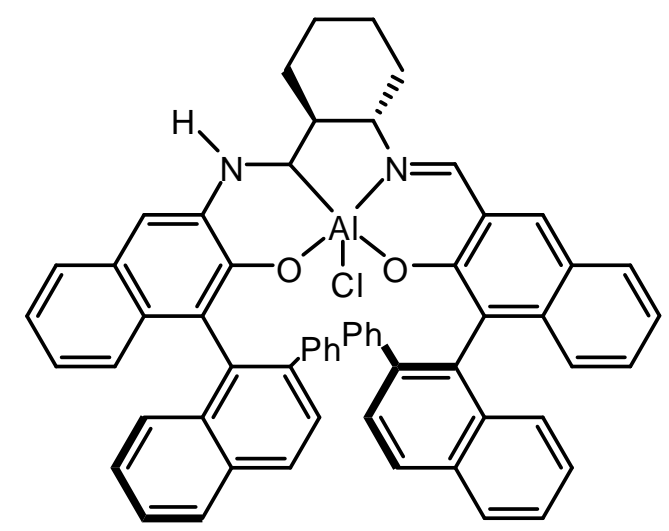

$\mathrm{Al}($ salalen)

Figure 8. Aluminium(salalen) complex as catalyst for asymmetric sulfoxidation in the presence of hydrogen peroxide [111]. 


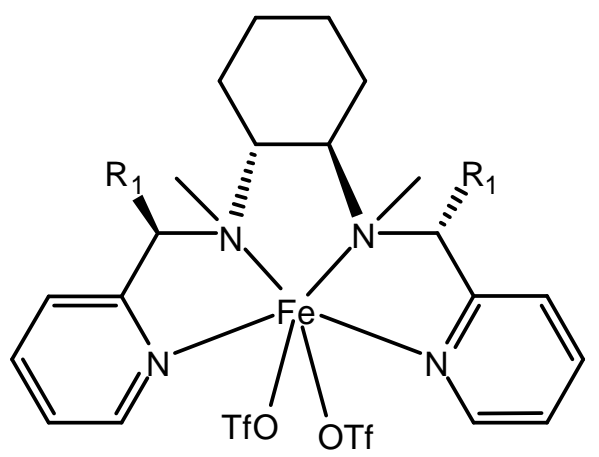

$$
\begin{aligned}
& \mathrm{R}_{1}=\mathrm{Ph} \\
& \mathrm{R}_{1}=4-t-\mathrm{Bu}-\mathrm{C}_{6} \mathrm{H}_{4} \\
& \mathrm{R}_{1}=\mathrm{H}
\end{aligned}
$$

Figure 9. Chiral iron complexes for enantioselective epoxidation of $\alpha, \beta$-unsaturated ketones [133].

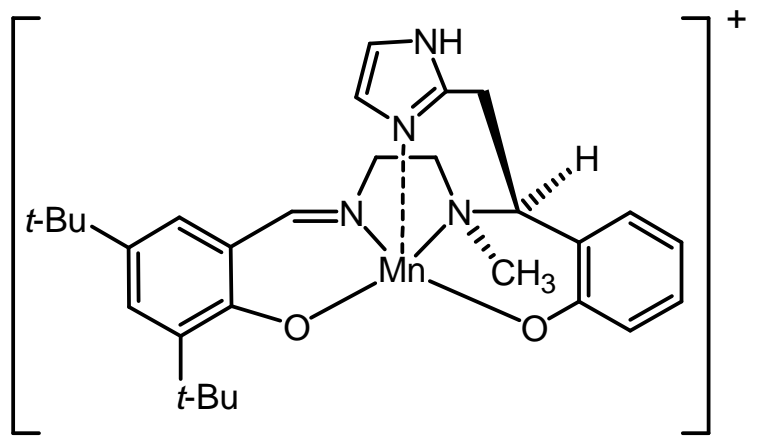

Figure 10. Chiral pentadentate dihydrosalen manganese complex for epoxidation of olefins [164] .

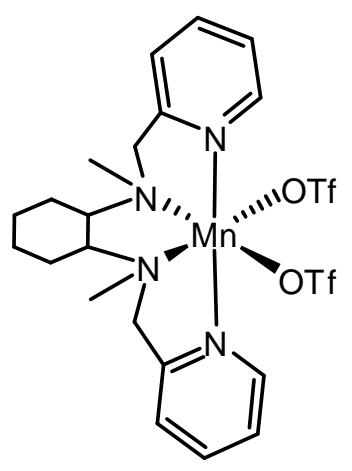

$1(R, R)$ -

$2(S, S)-$

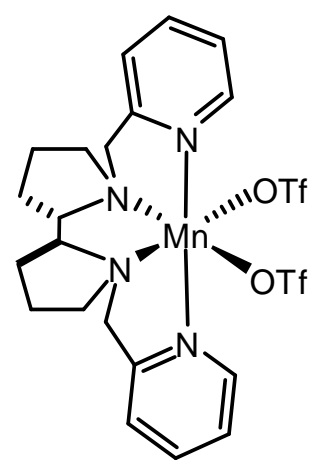

$3(S, S)-$

$\mathrm{OTf}=\mathrm{CF}_{3} \mathrm{SO}_{3}^{-}$

Figure 11. Chiral non-heme aminopyridine manganese complexes [170]. 

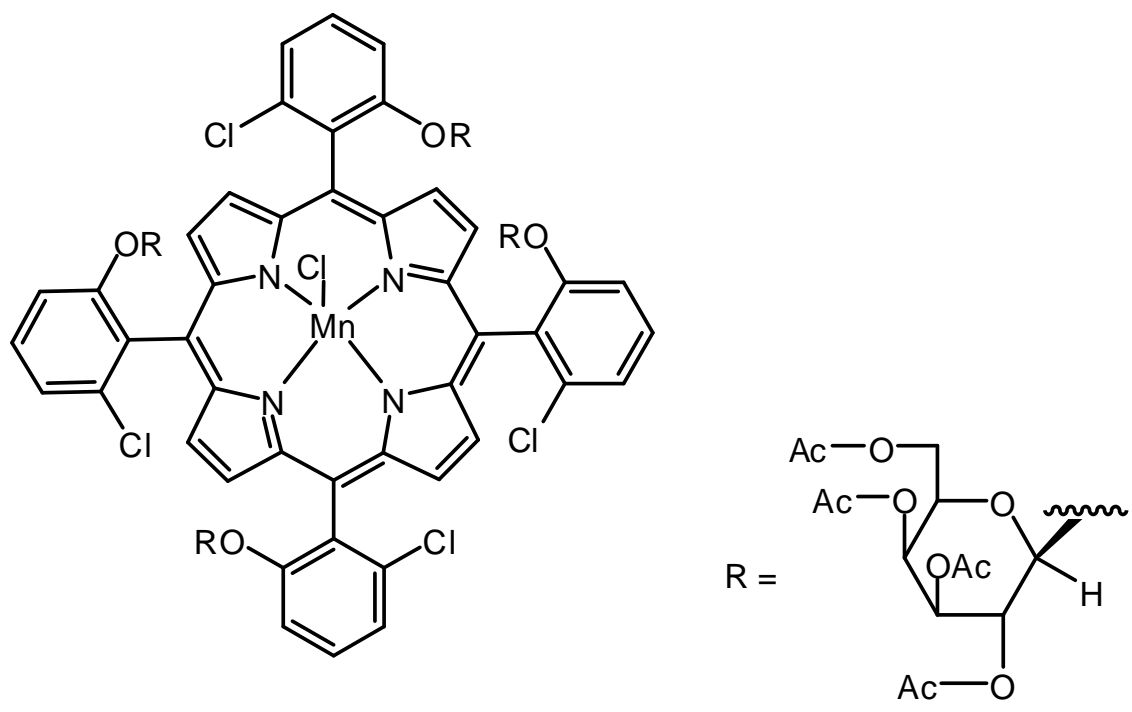

$\mathrm{R}=\mathrm{F}$

Figure 12. Chiral manganese porphyrins bearing glycosyl groups [172].

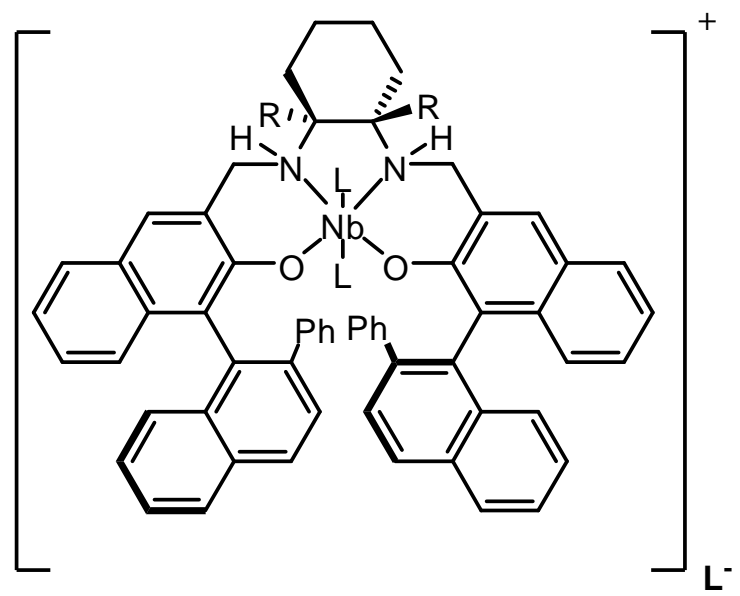

1: $\mathrm{R}=\mathrm{H}, \mathrm{L}=\mathrm{OiPr}$

2: $\mathrm{R}=\mathrm{Me}, \mathrm{L}=\mathrm{O} i \mathrm{Pr}$

Figure 13. Niobium(salan) complexes [123]. 

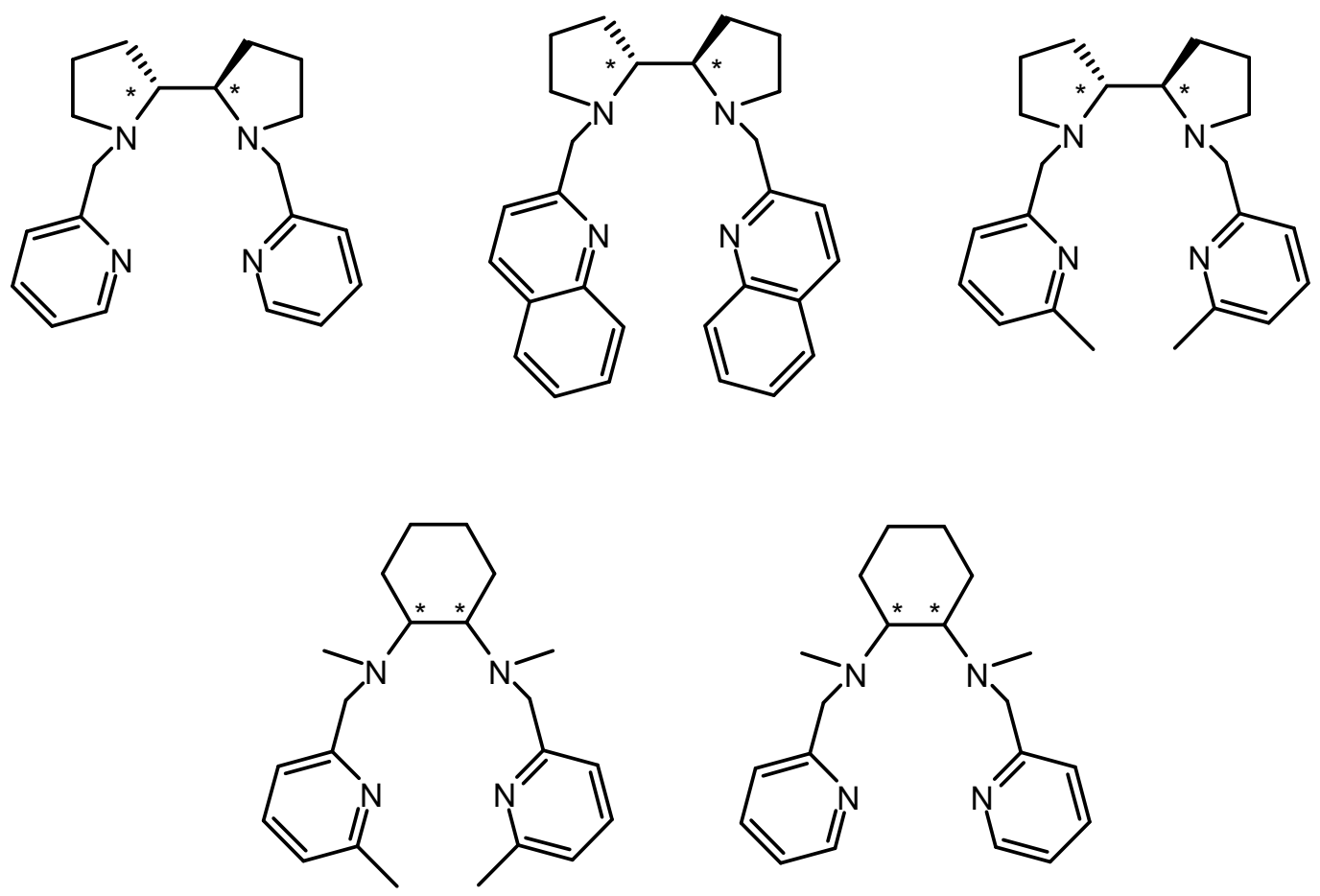

Figure 14. Optically active ligands used after iron complexation for asymmetric cisdihydroxylation [197].

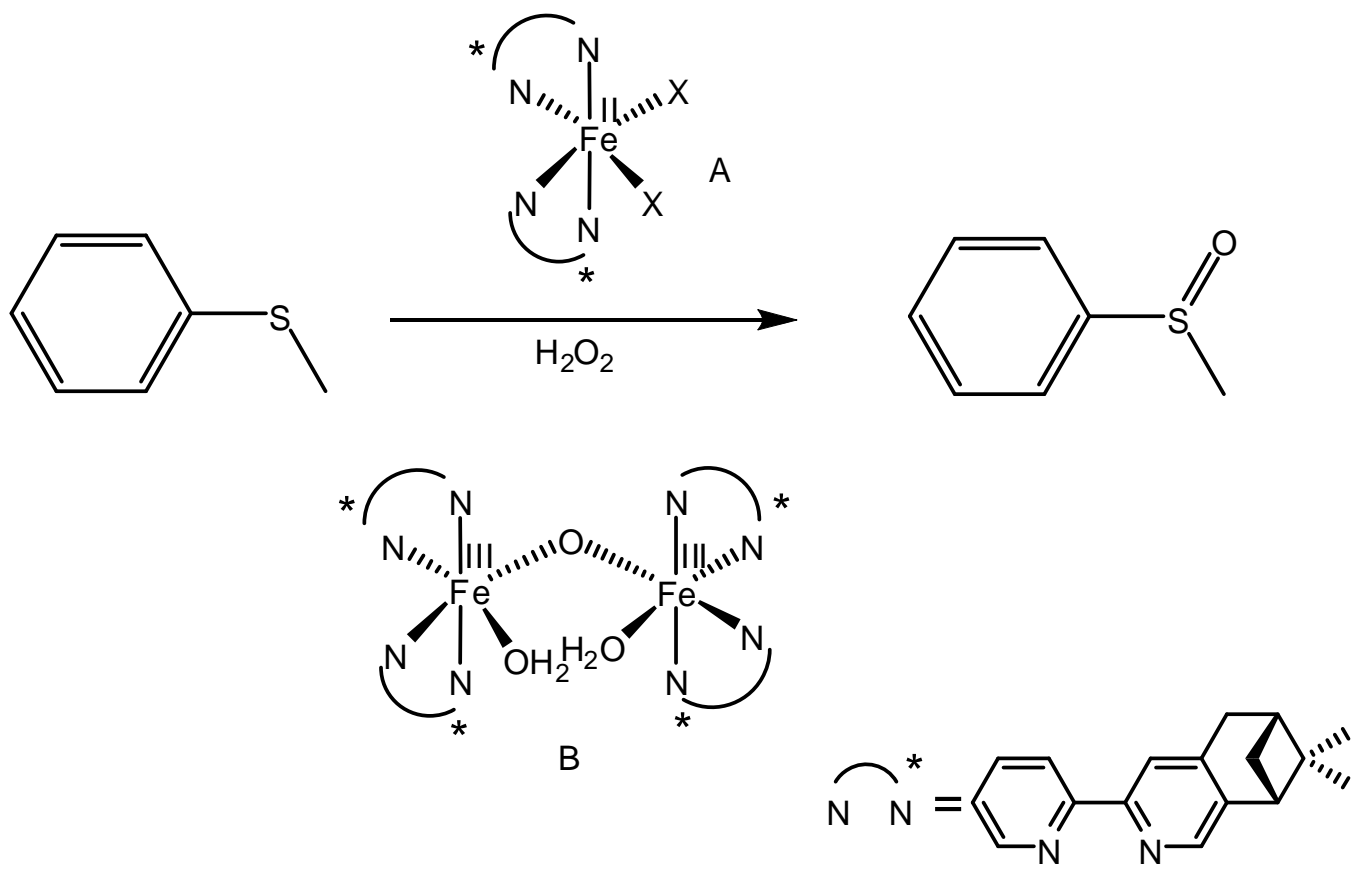

Scheme 1. Oxidation of sulfide catalyzed by complex A or B [29]. 


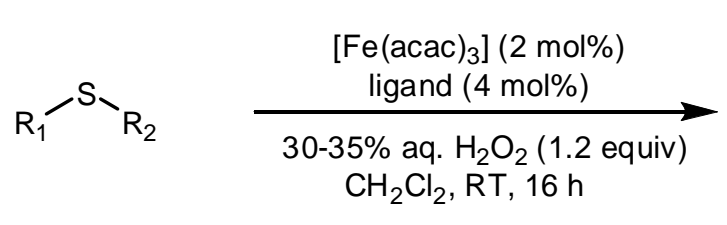<smiles>[2H][SH]([2H])([2H])=O</smiles>

Ligand $=$<smiles>CC(C)(C)C(CO)/N=C/c1cc(I)cc(I)c1O</smiles>

Scheme 2. Non-heme iron-catalyzed enantioselective sulfoxidation [24].

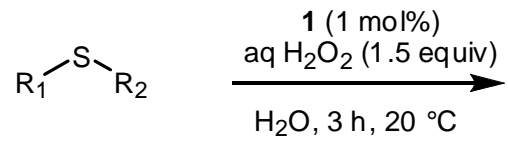

$\mathrm{R}_{1}=$ aryl or alkyl

$\mathrm{R}_{2}=\mathrm{Me}$ or $\mathrm{Et}$

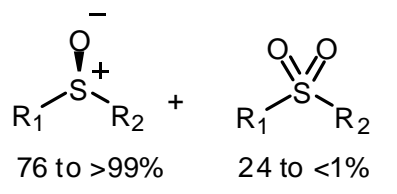

$\mathrm{R}_{1}=\operatorname{aryl} ; 81-96 \%$ ee

$\mathrm{R}_{2}=$ alkyl; $87-94 \%$ ee

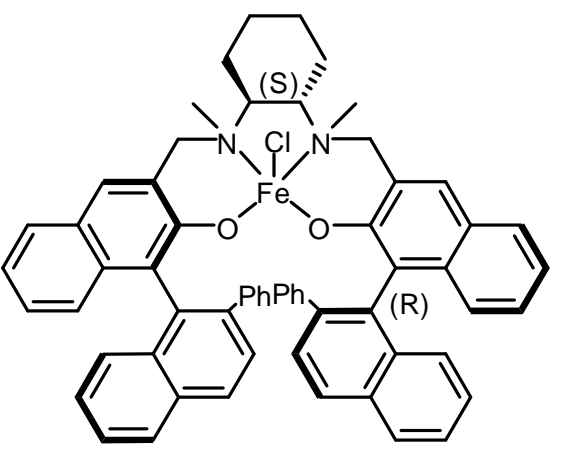

1

Scheme 3. Asymmetric oxidation of sulfides with Fe(salan) [32].

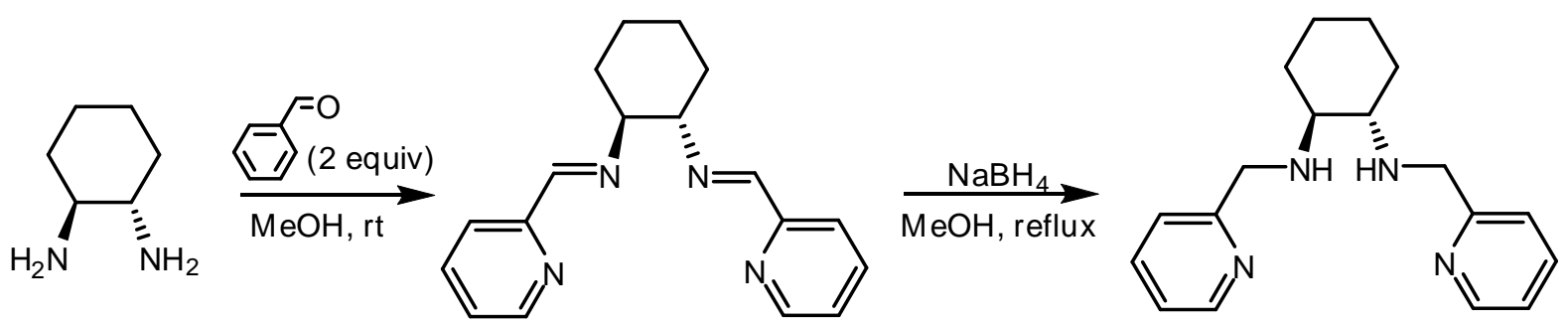

Scheme 4. Synthesis of ligands from a chiral cyclohexyl diamine backbone [57].<smiles>CC(C)(C)SSC(C)(C)C</smiles><smiles>O=CCOCCCCCCO</smiles><smiles>CC(C)(C)S[S](O)C(C)(C)C</smiles>

Scheme 5. Sulfoxidation of tert-butyl disulfide catalyzed by vanadium complexes [85]. 

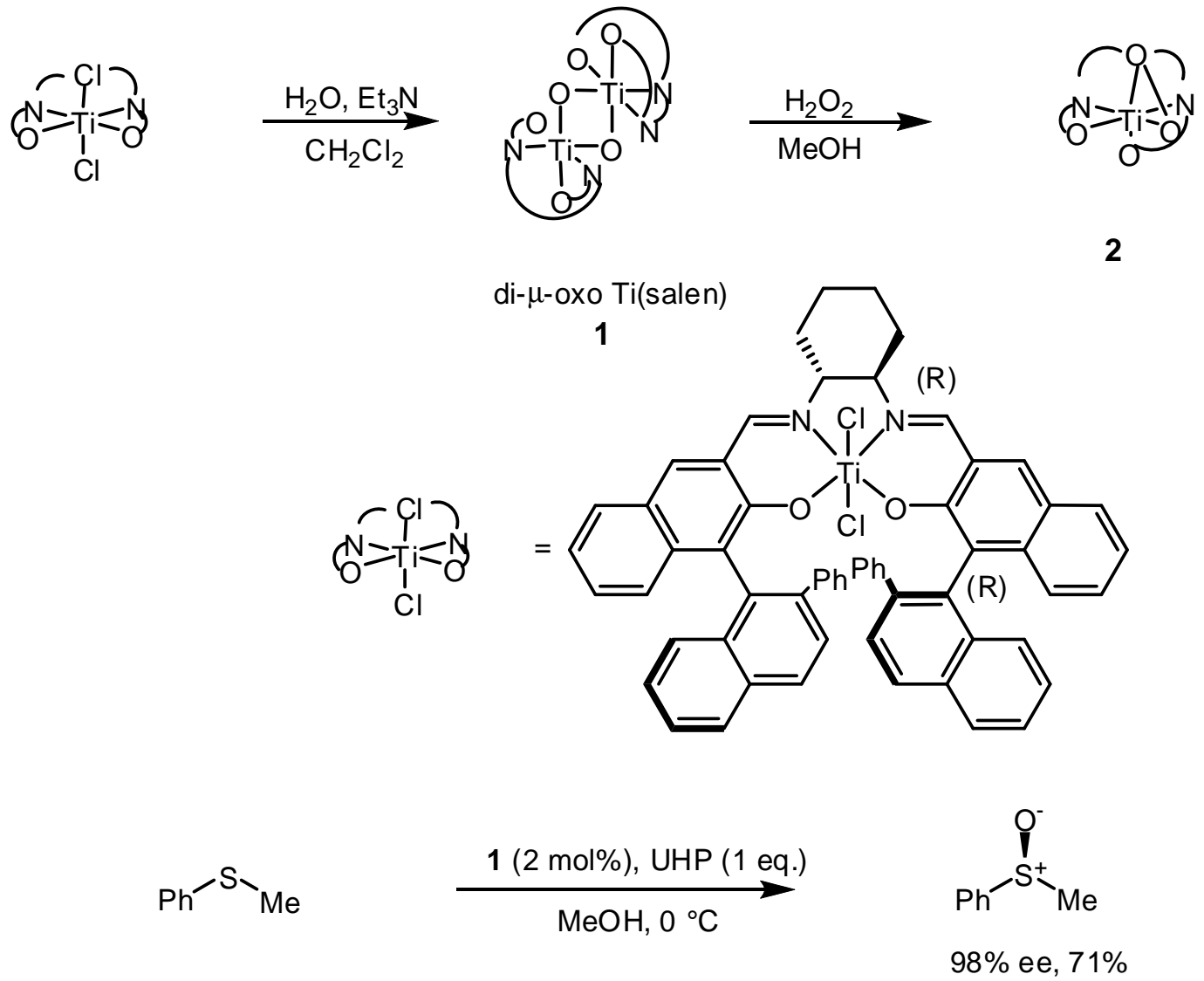

Scheme 6. Asymmetric oxidation by Ti(salen) complex [94].

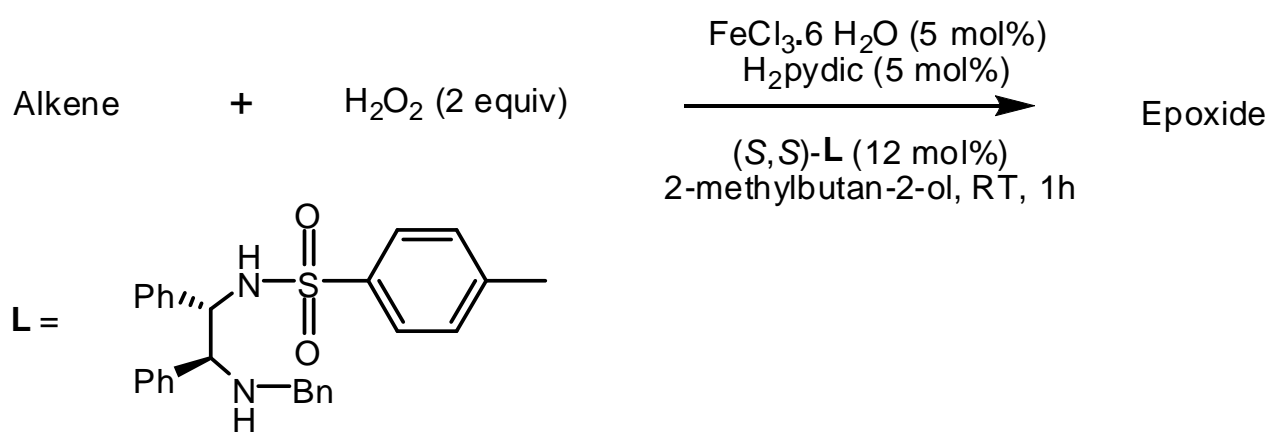

Scheme 7. Asymmetric epoxidation catalyzed by iron and chiral ligands bearing sulfonyl group [130]. 


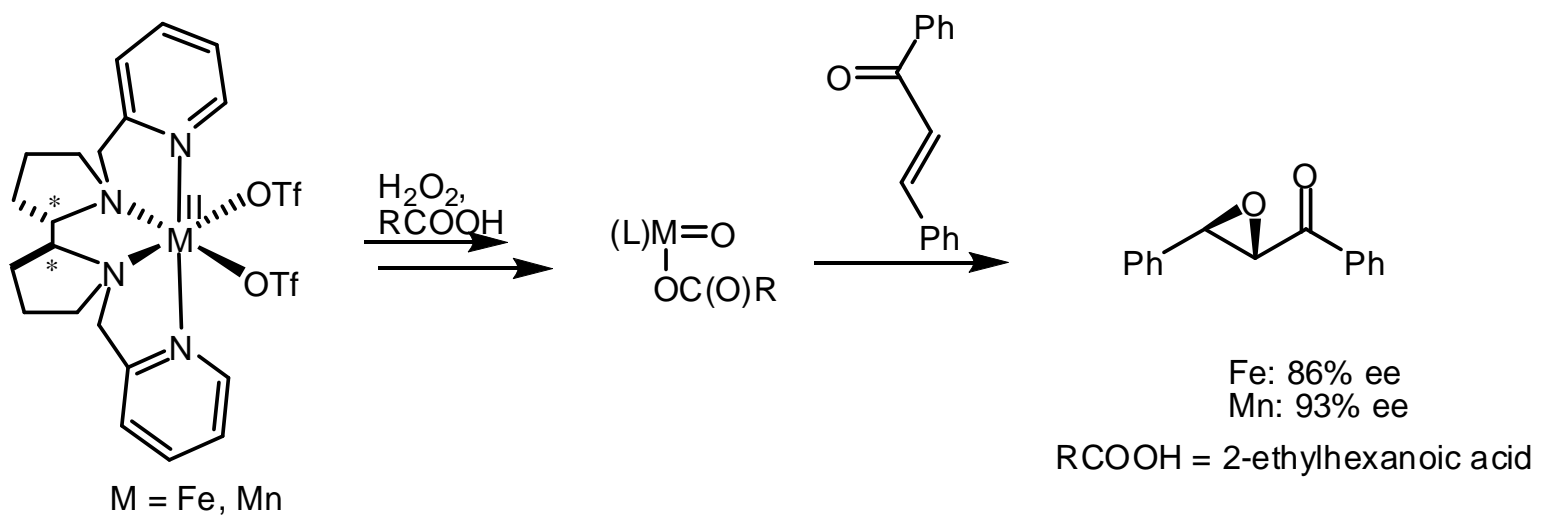

Scheme 8. Chiral bipyrrolidine ligand based iron and manganes complexes [132].

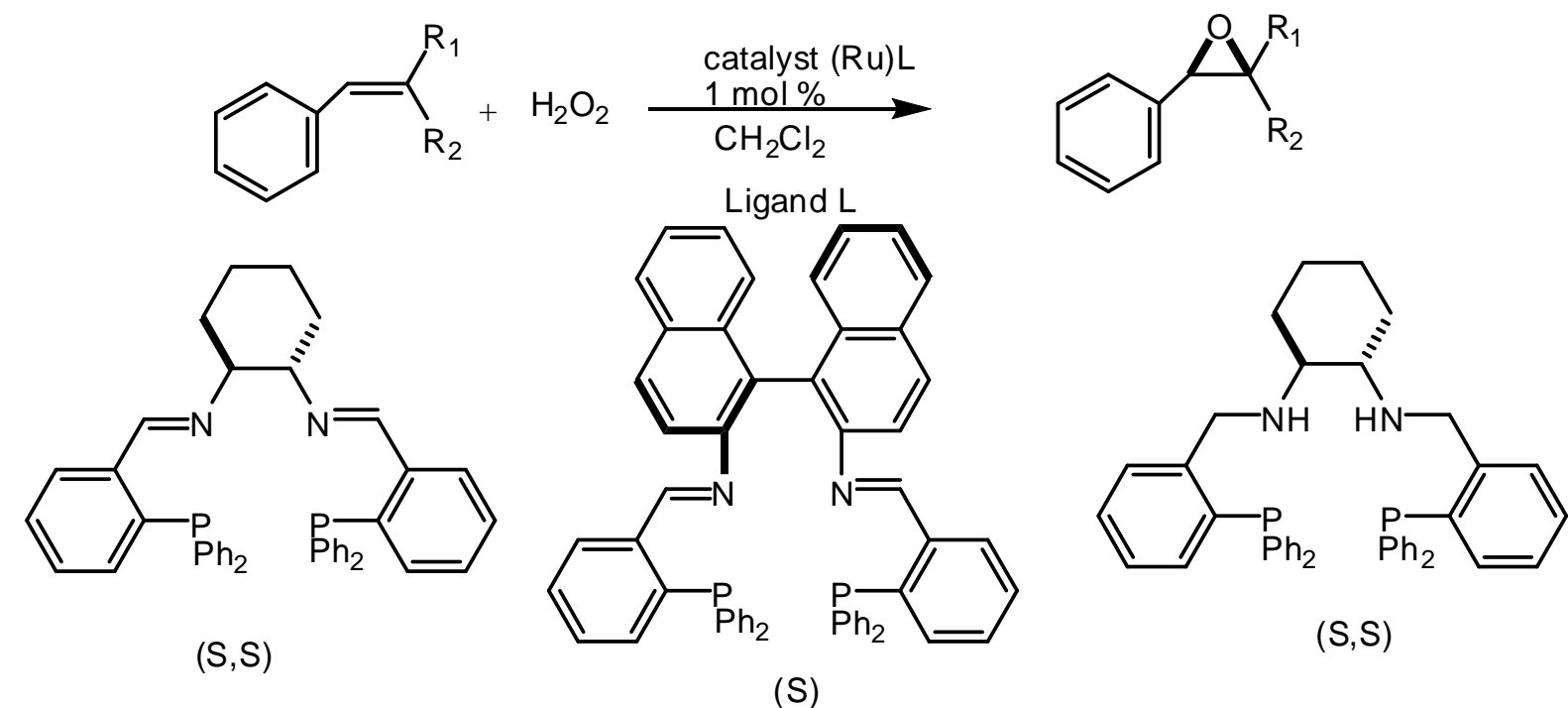

Scheme 9. Asymmetric epoxidation catalyzed by chiral tetradentate Ru(II) complexes [152].

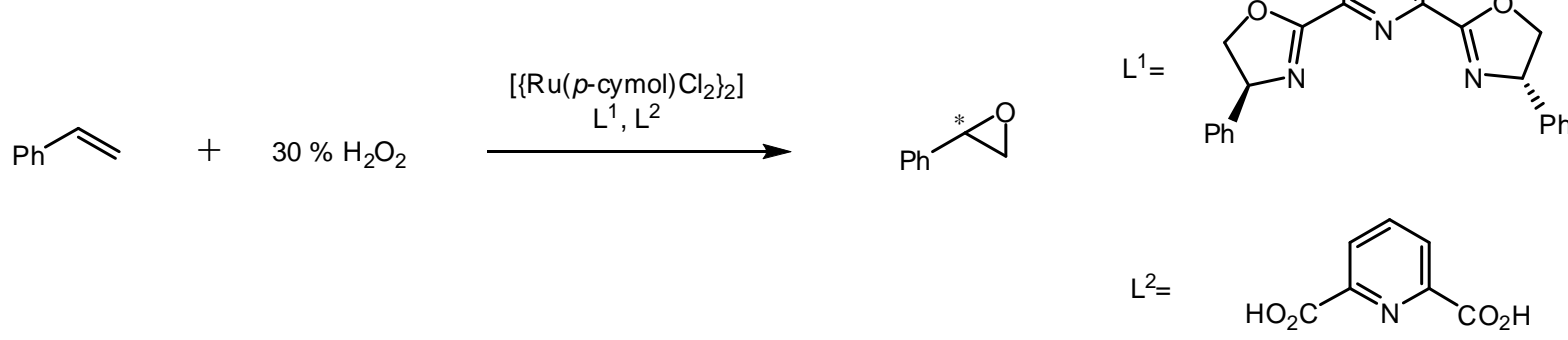

Scheme 10. Ruthenium-pybox- catalyzed asymmetric epoxidation of styrene [153]. 
<smiles>COC(=N)c1cccc(C(=O)OC)n1</smiles>

2

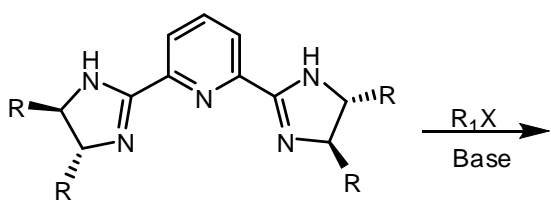

$3, \mathrm{R}=-\left(\mathrm{CH}_{2}\right)_{4}^{-}, 84 \%$ $3, \mathrm{R}=-\left(\mathrm{CH}_{2}\right)_{4}^{-}, 8$
$4, \mathrm{R}=\mathrm{Ph}, 94 \%$<smiles>[R]C1N=C(c2cccc(C3=N[C@@H]([R])[C@H]([R7])N3[R7])n2)N([R7])[C@H]1[R]</smiles>

5a-b, $\mathrm{R}=-\left(\mathrm{CH}_{2}\right)_{4}-$ 6a-I, $\mathrm{R}=\mathrm{Ph}$

Scheme 11. Synthesis of a Pybim library [156].<smiles>CC(=O)Nc1cc2c(cc1[N+](=O)[O-])OC(C)(C)C=C2</smiles>

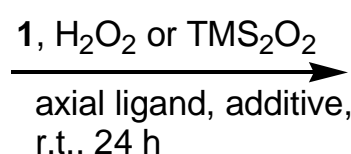<smiles>CC(C)(C)Nc1cc2c(cc1[N+](=O)[O-])OC(C)(C)C1OC21</smiles><smiles>CCC</smiles>
r.t., $24 \mathrm{~h}$

$+$

$\mathrm{Ph}^{*}=4-t-$ Butylphenyl

Scheme 12. Enantioselective epoxidation of chromene catalyzed by Mn(salen) complex [162].

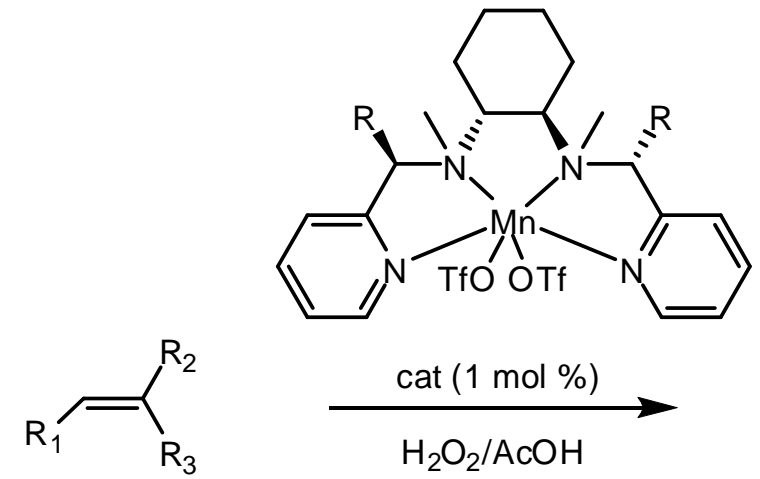<smiles>[R]C1OC1([R6])[2H]</smiles>

Up to $89 \%$ ee

Scheme 13. Asymmetric epoxidation of olefins catalyzed by chiral tetradentate N4 Manganese complexes [168]. 


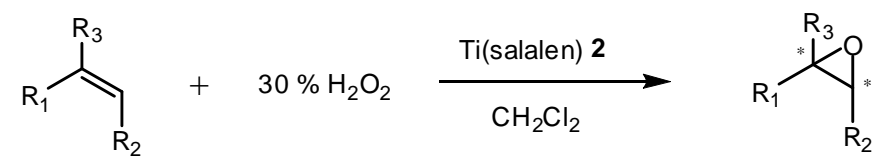

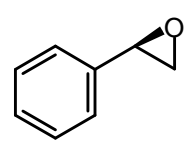

$93 \%$ ee<smiles>c1ccc2c(c1)CC1OC21</smiles>

$99 \%$ ee
$82 \%$ ee

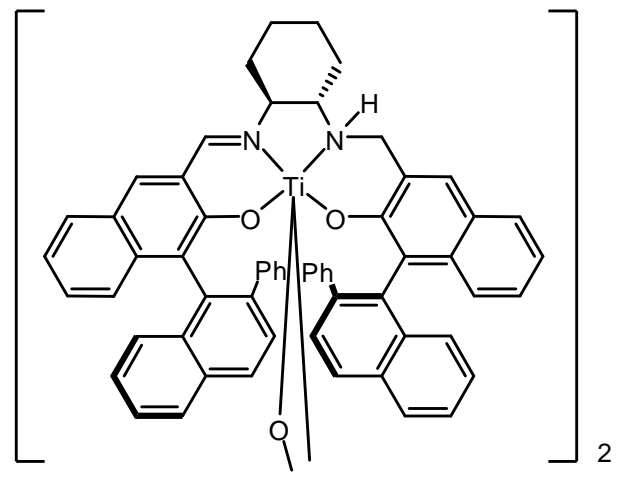

2

Scheme 14. Ti(salalen)-catalyzed asymmetric epoxidation [181].

$\longrightarrow 30 \% \mathrm{H}_{2} \mathrm{O}_{2} \underset{\mathrm{CH}_{2} \mathrm{Cl}_{2}}{\stackrel{\mathrm{Ti}(\text { salan })(5 \mathrm{~mol} \%)}{\longrightarrow}}$<smiles>c1ccc2c(c1)CC[C@@H]1O[C@H]21</smiles>

$73 \%, 95 \%$ ee

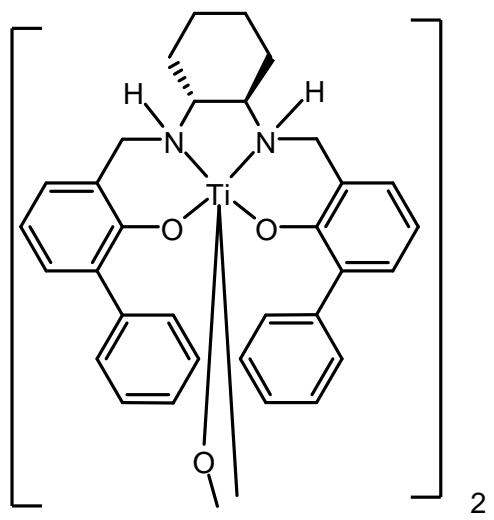

Scheme 15. Asymmetric epoxidation of 1,2-dihydronaphtalene with Ti(salan) complex [181]. 

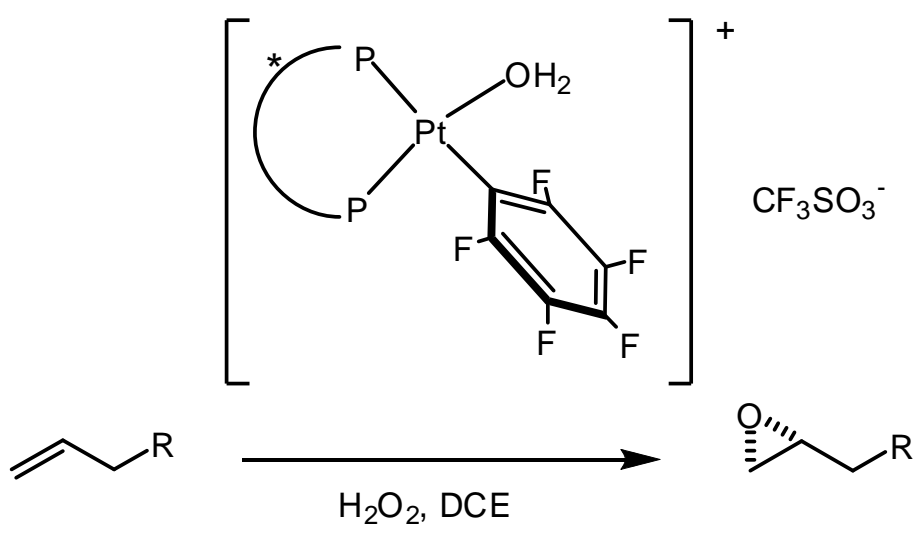

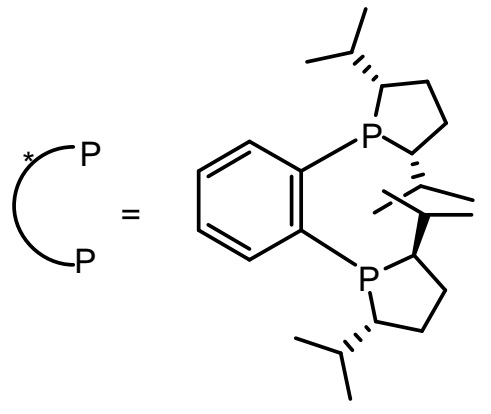

$(R, R, R, R)$

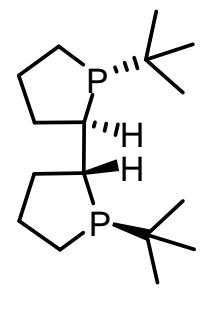

$(S, S, R, R)$

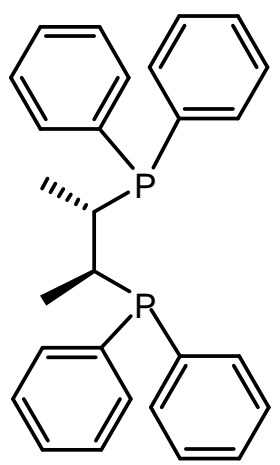

$(S, S)$

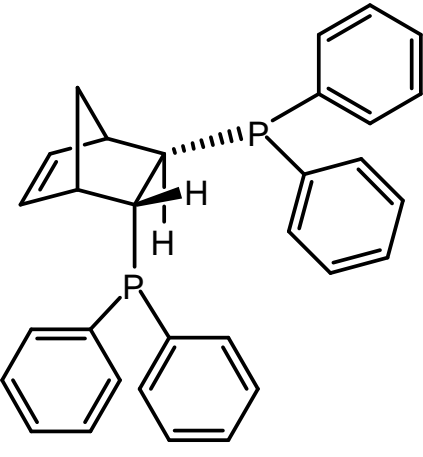

$(R, R)$

Scheme 16. Asymmetric epoxidation of terminal alkenes with hydrogen peroxide catalyzed by chiral Pt complexes [184].<smiles>CC1(C)C=Cc2ccccc2O1</smiles>

$$
\begin{aligned}
& 0.4 \mathrm{~mol} \% 6 \\
& 4.0 \mathrm{~mol} \% \text { Ac-D-Phg } \\
& \underset{\mathrm{CH}_{3} \mathrm{CN} / \mathrm{H}_{2} \mathrm{O}(19: 1)}{1.7 \text { equiv. } \mathrm{H}_{2} \mathrm{O}_{2}} \\
& -20^{\circ} \mathrm{C}, 5 \mathrm{~h}
\end{aligned}
$$
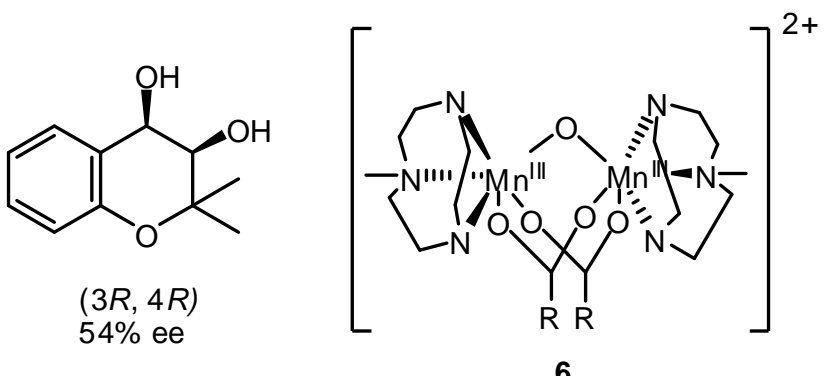

Scheme 17. Asymmetric cis-dihydroxylation of chromene with $\mathrm{H}_{2} \mathrm{O}_{2}$ catalyzed by manganese complex [199]. 

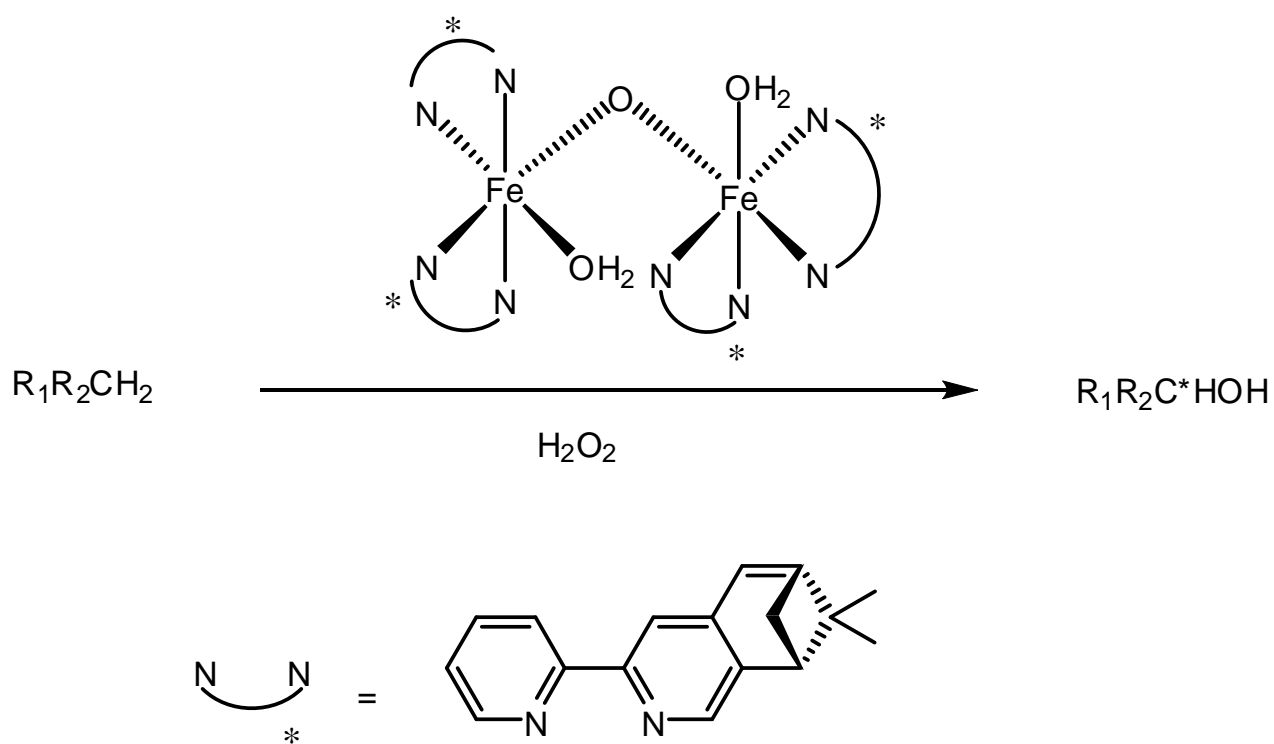

Scheme 18. Enantioselective hydroxylation of alkanes with $\mathrm{H}_{2} \mathrm{O}_{2}$ by non-heme iron complex [209]. 